\title{
SIMONE SHIBAO
}

\section{Análise comparativa entre a dosagem do lactato no líquor e sua detecção através da espectroscopia de prótons por ressonância magnética}

Tese apresentada à Faculdade de Medicina da Universidade de São Paulo para obtenção do título de Doutor em Ciências

Área de concentração: Radiologia

Orientadora: Prof. Dra. Claudia da Costa Leite

São Paulo 
Dados Internacionais de Catalogação na Publicação (CIP)

Preparada pela Biblioteca da

Faculdade de Medicina da Universidade de São Paulo

Creprodução autorizada pelo autor

\section{Shibao, Simone}

Análise comparativa entre a dosagem do lactato no líquor e sua detecção através da espectroscopia de prótons por ressonância magnética / Simone Shibao. -- São Paulo, 2010.

Tese (doutorado)--Faculdade de Medicina da Universidade de São Paulo. Departamento de Radiologia.

Área de concentração: Radiologia.

Orientadora: Claudia da Costa Leite.

Descritores: 1.Ácido láctico 2.Espectroscopia de ressonância magnética 3.Ressonância magnética 4.Encefalopatias 5.Mitocôndrias 6.Líquido cefalorraquidiano 7.Sistema nervoso central

USP/FM/SBD-056/10 


\section{Dedicatória}


Aos meus pais, pelo amor incondicional e pelo exemplo de vida.

A Jaciguara e Flávio, pela Sabrina, inspiração da minha vida.

Ao Carlos, pelo carinho, apoio e compreensão. 
Agradecimentos

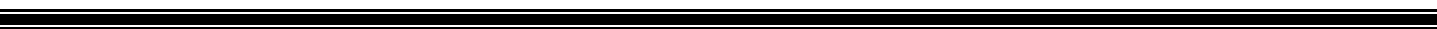


À minha orientadora, Profa. Dra. Claudia da Costa Leite, pelo incentivo e apoio para o desenvolvimento desse trabalho assim como de minha carreira profissional. Agradeço, especialmente, a amizade e o carinho.

Ao Prof. Dr. Fernando Kok, pelo auxílio inestimável no estudo das doenças mitocondriais, pelos seus ensinamentos e sua orientação, pelas sugestões e pelo incentivo durante o desenvolvimento desta pesquisa. Agradeço, de modo particular, o privilégio de convivermos profissionalmente, o que me permite um aprendizado constante.

Ao Dr. Leandro Tavares Lucato pelo apoio irrestrito para a realização deste trabalho, sugestões valorosas e incentivo nas horas mais difíceis.

À Dra. Maria Concepción Garcia Otaduy pelo auxílio inestimável na confecção dessa tese e pelo incentivo durante seu desenvolvimento.

Ao Dr. João Ricardo Sato, pela sua incomensurável colaboração na elaboração desta tese e sua presteza nas horas mais difíceis.

À Dra. Maria Cristina Chammas pela oportunidade de divulgar minha vocação pedagógica.

Ao Prof. Dr. Giovanni Guido Cerri pela oportunidade de participar do Instituto de Radiologia.

À Prof Dra. Ilka Regina, pois através do seu convite iniciei minha carreira no Hospital das Clínicas.

À Dra. Eloisa Gebrim, pela sua amizade.

Ao Prof. Dr. Sérgio Rosemberg, os preciosos ensinamentos que recebi desde a vida acadêmica e que se estendem a vida profissional, bem como pela sua agradável convivência e excelente bom humor. 
Às Doutoras Maria da Graça Morais Martin, Hae Won Lee e Paula Cristina Ricci pela amizade e apoio durante a elaboração deste trabalho.

À equipe de anestesia, Dr. Ricardo, Dra. Angela, Dra. Ana, Dr. Robson e demais membros da equipe, pelo auxílio e disponibilidade para a realização das anestesias necessárias.

Ao Dr André Pessoa pela avaliação dos pacientes desta pesquisa.

À Dra Emília Katiane Leão pela colaboração na coleta dos dados para esta pequisa.

Ao Dr Felippe Borlot, pela colaboração na coleta dos dados para esta pequisa.

À equipe de neuropediatria, pelo encaminhamento dos pacientes e confiança no potencial deste trabalho.

Aos pacientes pela sua estimável e honrosa confiança de participar desta pesquisa.

Aos biomédicos, à equipe da enfermagem e ao administrativo do Setor de Ressonância Magnética do HCFMUSP, pela colaboração nesse trabalho no atendimento aos pacientes.

A todos aqueles que de alguma maneira contribuíram para o desenvolvimento deste trabalho, e que não foram citados nominalmente, agradeço a honra de terem partilhado comigo este período tão importante da minha vida. 


\section{Normalização adotada}

Esta dissertação ou tese está de acordo com as seguintes normas, em vigor no momento desta publicação:

Referências: adaptado de International Committee of Medical Journals Editors (Vancouver)

Universidade de São Paulo. Faculdade de Medicina. Serviço de Biblioteca e Documentação. Guia de apresentação de dissertações, teses e monografias. Elaborado por Anneliese Carneiro da Cunha, Maria Julia de A. L. Freddi, Maria F. Crestana, Marinalva de Souza Aragão, Suely Campos Cardoso, Valéria Vilhena. 2a ed. São Paulo: Serviço de Biblioteca e Documentação; 2005.

Abreviaturas dos títulos dos periódicos de acordo com List of Journals Indexed in Index Medicus. 
Sumário

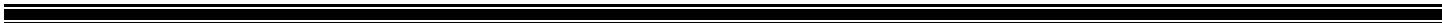


Lista de abreviaturas

Lista de símbolos

Lista de tabelas

Lista de gráficos

Lista de figuras

Resumo

Summary

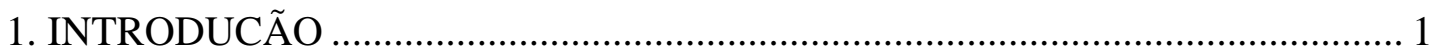

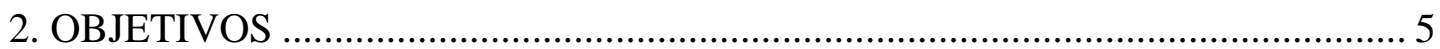

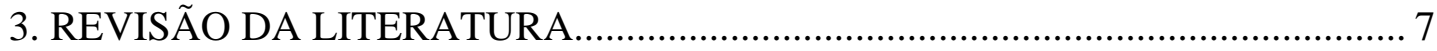

3.1 Conceito das doenças mitocondriais ............................................................. 8

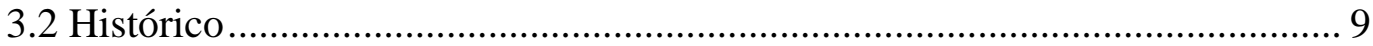

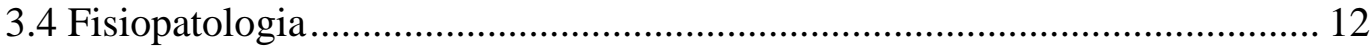

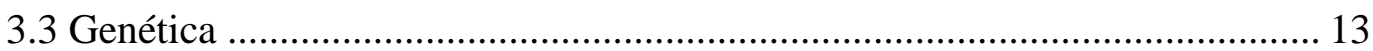

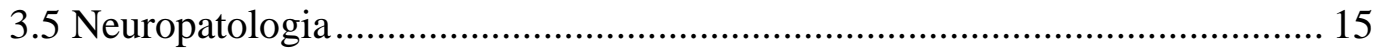

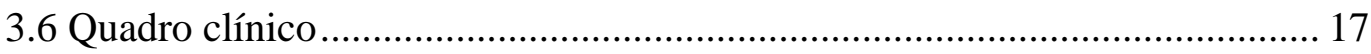

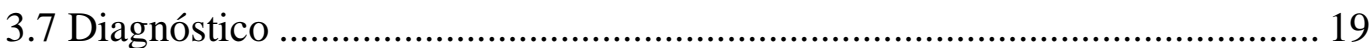

3.8 Ressonância Magnética............................................................................... 21

3.8 Espectroscopia de prótons por Ressonância Magnética................................ 24

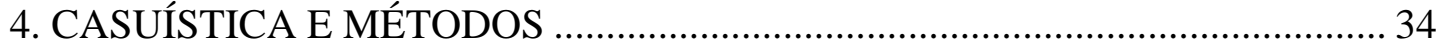

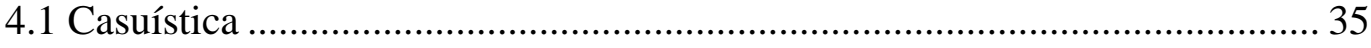

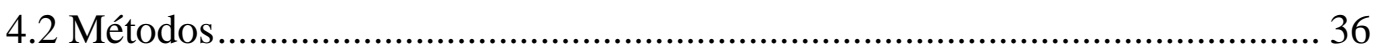

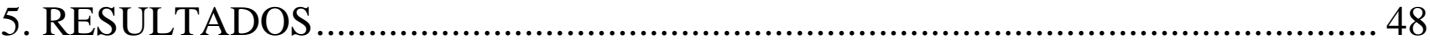

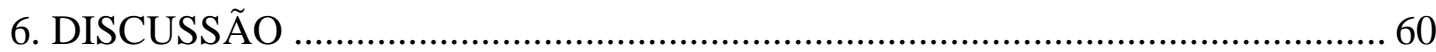

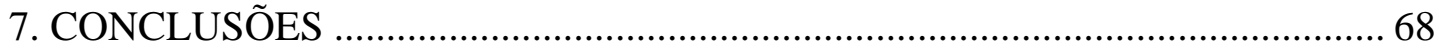

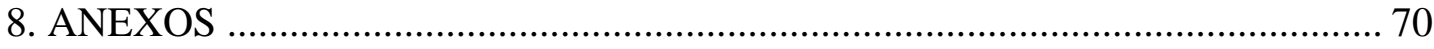

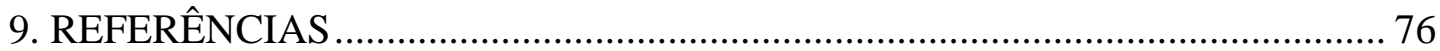


Listas

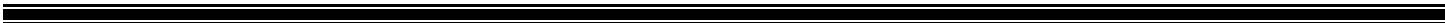




\section{LISTA DE ABREVIATURAS}

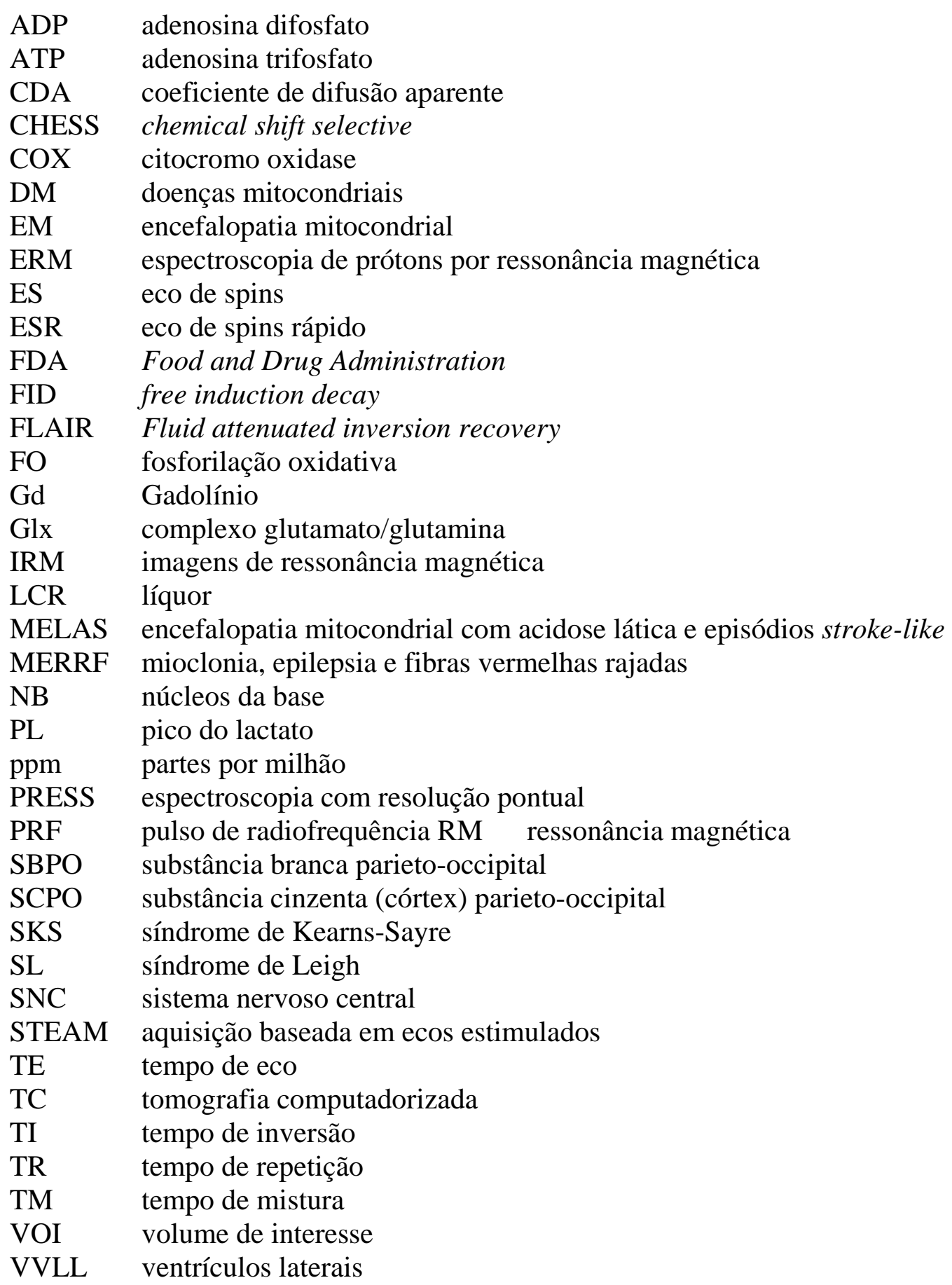




\section{LISTA DE SÍMBOLOS}

$\begin{array}{ll}\mathrm{dL} & \text { decilitro } \\ \mathrm{Hz} & \text { Hertz } \\ \mathrm{L} & \text { litro } \\ \mathrm{mg} & \text { miligrama } \\ \mathrm{mL} & \text { mililitro } \\ \mathrm{Mmol} & \text { milimolar } \\ \mathrm{T} & \text { Tesla } \\ * & \text { multiplicação } \\ = & \text { igual a }\end{array}$




\section{LISTA DE TABELAS}

Página

TABELA 1 Parâmetros técnicos de RM das sequências utilizadas....................... 40

TABELA 2 Lista dos pacientes, relação da identificação (+) ou não identificação do PL à ERM, nas diferentes localizações estudadas, e resultados das dosagens bioquímicas do lactato liquórico e sanguíneo

TABELA 3 Relação de pacientes, volumes do vóxel nos VVLL, valores do PL à RM calculado pelo LCmodel, erro percentual do cálculo do valor do PL através do Lcmodel e resultados das dosagens bioquímicas do lactato liquórico e sanguíneo

TABELA 4 Análise de Correlação Linear de Pearson das variáveis PL à ERM, lactato no LCR e lactato sérico pareadas duas a duas, valores dos coeficientes de $\mathrm{p}$ 


\section{LISTA DE GRÁFICOS}

Página

GRÁFICO 1 Distribuição dos pacientes por sexo.

GRÁFICO 2 Gráfico de dispersão entre os valores obtidos de lactato liquórico (LCR) e sanguíneo (SG

GRÁFICO 3 Gráfico de dispersão entre os valores obtidos de lactato à ERM (RM) e o liquórico (LCR).

GRÁFICO 4 Gráfico de dispersão entre os valores obtidos de lactato à ERM (RM) e o sanguíneo (LCR

GRÁFICO 5 Gráfico de dispersão entre os valores obtidos de lactato à ERM (RM) e o liquórico (LCR) considerando os valores com erro inferiores a $30 \%$. 58

GRÁFICO 6 Gráfico de dispersão entre os valores obtidos de lactato à ERM (RM) e o sanguíneo (LCR) considerando os valores com erro inferiores a $30 \%$. 59 


\section{LISTA DE FIGURAS}

Página

FIGURA 1 Imagem no plano axial ponderada em T2 demonstrando a localização do volume de interesse na região dos núcleos da base e do tálamo

FIGURA 2 Imagem no plano axial ponderada em T2 demonstrando a localização do volume de interesse na cortical parieto-occipital.

FIGURA 3 Imagem no plano axial ponderada em T2 demonstrando a localização do volume de interesse na substância branca parieto-occipital 45

FIGURA 4 Imagem no plano axial ponderada em T2 demonstrando a localização do volume de interesse nos ventrículos laterais 45

FIGURA 5 Imagem no plano axial ponderada em T2 demonstrando a localização do volume de interesse nos ventrículos laterais e o espectro correspondente evidenciando o PL

FIGURA 6 Imagem no plano axial ponderada em T2 demonstrando a localização do volume de interesse na substância branca parietoccipital e o espectro correspondente evidenciando o PL

FIGURA 7 Imagem no plano axial ponderada em T2 demonstrando a localização do volume de interesse nos núcleos da base e o o espectro correspondente evidenciando o PL 
Resumo

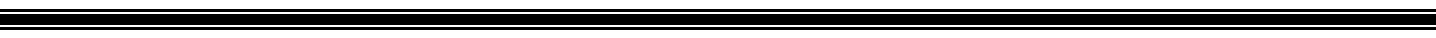


Shibao S. Análise comparativa entre a dosagem do lactato no líquor e sua detecção através da espectroscopia de prótons por ressonância magnética [tese]. São Paulo: Faculdade de Medicina, Universidade de São Paulo; 2010. 91 p.

INTRODUÇÃO: A dosagem bioquímica do lactato no líquor (LCR) é um procedimento rotineiro e necessário na investigação diagnóstica e no acompanhamento evolutivo de várias doenças neurológicas, como, por exemplo, as doenças mitocondriais (DM). Pacientes com DM e comprometimento do sistema nervoso central frequentemente apresentam aumento do lactato no LCR. O lactato no LCR também pode ser detectado através da espectroscopia de prótons através da ressonância magnética (ERM), uma técnica não invasiva que pode ser empregada juntamente com as imagens estruturais obtidas através da ressonância magnética (RM). Nosso objetivo neste estudo é avaliar a existência ou não de correlação entre a dosagem bioquímica do lactato no LCR e no sangue e a sua quantificação através da ERM em pacientes em investigação de encefalopatia mitocondrial. Não é de nosso conhecimento a existência de estudos semelhantes in vivo na literatura médica. MÉTODOS: 22 pacientes (idades entre 9 meses e 20 anos) em investigação diagnóstica por suspeita clínica de encefalopatia relacionada a DM participara deste estudo prospectivo realizado entre novembro de 2005 a novembro de 2006. Foram comparados os valores do lactato nas dosagens séricas e liquóricas. Todos os pacientes realizaram RM e ERM e, quando presente, analisou-se o pico do lactato (PL). Os dados da quantificação do lactato obtidos nestas três modalidades foram comparados. RESULTADOS: A análise de correlação demonstrou evidências de associação entre as variáveis PL à ERM e lactato liquórico $(p=0,001)$; não foi evidenciada correlação entre os valores do PL à ERM e as medidas sanguíneas dessa substância $(p=0,736)$ e entre as dosagens bioquímicas liquórica e sanguínea $(p=0,937)$. CONCLUSÕES: Este estudo demonstrou a existência de correlação entre a dosagem bioquímica do lactato no LCR e o PL obtido através de ERM. A ERM do LCR é uma técnica factível e recomendamos que a mesma seja empregada rotineiramente em pacientes com suspeita ou em seguimento de DM com comprometimento do sistema nervoso central.

Descritores: 1.Ácido láctico 2.Espectroscopia de ressonância magnética 3.Ressonância magnética 4.Encefalopatias 5.Mitocôndrias 6.Líquido cefalorraquidiano 7.Sistema nervoso central 
Summary 
Shibao S. Comparative analysis between lactate biochemical dosage in cerebrospinal fluid and its detection by proton magnetic resonance spectroscopy [thesis]. São Paulo: “Faculdade de Medicina, Universidade de São Paulo”; 2010. $91 \mathrm{p}$.

INTRODUCTION: The cerebrospinal fluid (CSF) lactate biochemical dosage is a routine and a requisite procedure to evaluate and to monitor many neurological diseases, such as mitochondrial disease (MD). Patients with MD and central nervous system (CNS) involvement, usually show an increase of CSF lactate. Another choice to study the lactate instead of CSF biochemical dosage is the CSF magnetic resonance proton spectroscopy (SRM), a noninvasive technique, which can be employed as an adjunct tool with structural magnetic resonance imaging (MRI). Our objective is to study the correlation between the CSF and blood lactate dosages and the SRM lactate quantification in patients under investigation for the MD encephalopathy. To our knowledge there is no report of similar studies in vivo in the literature. METHODS: 22 patients (aging 9 months to 20 years old) under investigation for MD encephalopathy were elected for this prospective study between November 2005 and December 2006. The lactate levels were analyzed by biochemical dosages in the CSF and blood serum. Brain MRI was performed for all patients and the lactate peak (LP) obtained from SRM was analyzed. All lactate level data obtained from the three different sources were compared. RESULTS: The statistical analysis demonstrated a correlation between the LP at SRM and the CSF lactate dosage ( $\mathrm{p}=0.0001)$; no correlation was observed between the LP and the blood lactate $(p=0.736)$ as well the blood lactate and CSF lactate $(p=0.937)$. CONCLUSION: Our study showed correlation between the lactate level in the CSF biochemical dosage and the LP found on SRM. The CSF SRM is tangible technique and we recommend it to be applied in the daily clinical practice to evaluate suspicious and diagnosed CNS compromised ME patients.

Descriptors: 1.Lactic acid 2.Magnetic resonance spectroscopy 3.Magnetic resonance 4. Brain diseases 5.Mitochondria 6.Cerebrospinal fluid 7.Central nervous system 


\section{1- Introdução}


O lactato no líquor (LCR) é um parâmetro fundamental na investigação diagnóstica e no acompanhamento evolutivo de várias doenças neurológicas. Sua quantificação é realizada através da dosagem bioquímica, sendo obtida uma amostra através da punção, usualmente lombar, um procedimento invasivo e rotineiro. Muitas dessas doenças também requerem uma avaliação por imagem dos pacientes e a ressonância magnética $(\mathrm{RM})$ é o exame de escolha para a caracterização de lesões estruturais e alterações metabólicas do encéfalo.

Dentre as doenças que cursam com aumento de lactato no LCR, destacam-se as doenças mitocondriais (DM), um grupo grande e heterogêneo de doenças e um dos maiores grupos de doenças metabólicas hereditárias. Apresentam em comum o comprometimento da fosforilação oxidativa (FO), que é a via fundamental do metabolismo celular. Assim, qualquer órgão pode ser comprometido; entretanto, o sistema nervoso central (SNC) e os músculos são os tecidos mais freqüentemente afetados devido à dependência entre a sua produção energética e a fosforilação oxidativa mitocondrial. Como consequência da interrupção desse processo, a geração de energia ocorre através do metabolismo anaeróbio, originando a produção e o acúmulo de lactato que, apesar de não ser um marcador exclusivo dessas enfermidades, é uma substância importante na avaliação das mesmas.

O diagnóstico das DM é complexo e envolve muitos testes, incluindo a dosagem bioqímica do lactato no LCR e os exames de imagem, destacando-se a RM, pois é o que permite a avaliação de alterações morfológicas e metabólicas do encéfalo. Em relação à análise metabólica através da espectroscopia de prótons por 
ressonância magnética (ERM), ressalta-se a caracterização da presença ou não do pico de lactato (PL), substância essa que é marcadora da interrupção do ciclo de respiração aeróbica celular.

A caracterização através da ERM do PL no LCR e no parênquima cerebral também aparenta ser um instrumento útil no diagnóstico e monitorização de pacientes com DM na prática clínica (Mathews, Andermann et al., 1993; Pavlakis, Kingsley et al., 1998). Lin e cols. observaram, em uma série de vinte e nove pacientes com DM, que a caracterização do PL é um achado frequente, tanto no LCR quanto no parênquima; os autores também evidenciaram uma alta correlação entre a presença de lactato no SNC com outros marcadores clínicos desse grupo de doenças (Lin, Crawford et al., 2003).

Quanto à caracterização do PL no LCR, seja em indivíduos sãos, seja em pacientes com aumento do lactato liquórico, há certa controvérsia na literatura. Alguns estudos com voluntários sãos e outros com análises comparativas entre pacientes e grupos-controle demonstram a ausência do PL no LCR e no parênquima encefálico (Duyn, Gillen et al., 1993; Soher, Hurd et al., 1996). Contudo, Braun e cols. (Braun, Gooskens et al., 2003) demonstraram que, mesmo com valores normais de lactato no LCR, o PL pode ser caracterizado à ERM do LCR; destaca-se, outrossim, uma ressalva em relação a esse trabalho, tanto pelo número limitado de pacientes com amostra do LCR (oito de vinte e quatro), como também pelo tempo transcorrido entre os exames e as coletas, que variou de um dia a quatro semanas. 
Diversos artigos na literatura médica referem a presença do aumento do pico de lactato no LCR através da ERM, porém, não existe referência à correlação in vivo entre a sua dosagem bioquímica e a sua quantificação pela ERM.

Por suas características, as doenças mitocondriais constituem o modelo de eleição para a investigação in vivo da existência ou não da correlação entre a dosagem do lactato no liquor e a sua caracterização através de ERM.

Assim sendo, esta pesquisa vem perscrutar as seguintes questões: se há caracterização do PL no LCR, mesmo quando a dosagem bioquímica está dentro dos valores considerados normais e se existe correlação da análise quantitativa aferida a partir do PL à ERM nos ventrículos laterais e a quantificação dessa substância através de método bioquímico nos pacientes com DM. 
2 - Objetivos

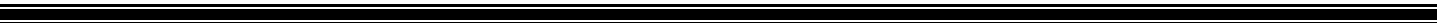


1- Verificar a existência de correlação entre os valores do lactato nas dosagens séricas e liquóricas;

2- Comparar a presença do pico do lactato na espectroscopia de prótons dos pacientes em quatro localizações (ventrículos laterais, núcleos da base, substância branca e córtex parietoccipital);

3- Verificar a existência de correlação entre a presença do pico do lactato nos ventrículos laterais na espectroscopia de prótons dos pacientes com $\mathrm{DM}$ e as dosagens séricas e liquóricas do mesmo. 
3 - Revisão da literatura

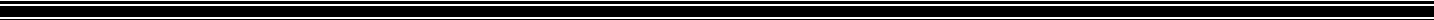




\section{1- Conceito de doença mitocondrial}

As DM, também conhecidas como mitocondriopatias, são doenças metabólicas caracterizadas por disfunção da cadeia respiratória, ou seja, da fosforilação oxidativa (FO) e constituem um grupo vasto de desordens clínicas decorrentes de mutações em genes mitocondriais ou genes nucleares; atualmente, são denominadas de doenças da cadeia respiratória (Hanna, Nelson, 1999; Leonard, Schapira, 2000; von Kleist-Retzow, Schauseil-Zipf et al., 2003; Zeviani, Di Donato, 2004; DiMauro, Schon, 2008).

Qualquer sistema pode ser afetado; o encéfalo e os músculos, porém, são os tecidos mais freqüentemente comprometidos devido ao fato de a sua produção energética depender da fosforilação oxidativa mitocondrial (Luft, 1994; Hanna, Nelson, 1999; Finsterer, 2006). Denomina-se encefalopatia mitocondrial (EM) o envolvimento encefálico pela doença (Filosto, Mancuso, 2007).

Dentre as doenças mitocondriais, as principais síndromes clínicas que, predominantemente, cursam com EM, se destacam as seguintes: a síndrome de Leigh; a síndrome de Kearns-Sayre; a encefalopatia com mioclonia, epilepsia e fibras vermelhas rajadas (da sigla em inglês: MERRF) e a encefalopatia mitocondrial com acidose lática e episódios stroke-like (da sigla em inglês: MELAS) (Zeviani, Di Donato, 2004; Finsterer, 2006). Outras síndromes clínicas cursam com manifestações que não envolvem o SNC e assim estão além do escopo deste trabalho; desta maneira, estas síndromes, tais como a neuropatia óptica hereditária de Leber, a 
síndrome de Pearson, a oftalmoplegia externa progressiva e a miopatia infantil com acidose lática, não serão abordadas. Salienta-se, também, que existe uma grande variedade na apresentação clínica, assim, muitos pacientes manifestam sinais e sintomas que não se encaixam em uma destas síndromes clínicas.

\section{2- Histórico das doenças mitocondriais}

Em 1960, estudos em mitocôndrias de fígado de rato já demonstravam que essa organela é o sítio da respiração celular e da fosforilação regulada pela respiração (Luft 1994).

Dois anos depois, Rolf Luft publicou o primeiro relato de doença mitocondrial, quando descreveu uma paciente de trinta anos, cujos sintomas iniciaram-se aos 7 anos de vida, que apresentava polidipsia sem poliúria, acentuada sudorese, ingesta calórica elevada apesar de reduzido índice de massa corpórea e fraqueza muscular. A função tireoidiana era normal; a taxa de metabolismo basal, no entanto, era muito elevada, fato que o fez pressupor que mecanismos reguladores do consumo de oxigênio em nível celular estivessem implicados, direcionando assim a investigação para a mitocôndria da musculatura esquelética (Luft, Ikkos et al., 1962).

No início da década de 1970, já era conhecido o fato de que alterações da cadeia respiratória, sem ou com alterações estruturais da mitocôndria, ocorriam em algumas miopatias, mesmo sem o alto consumo de oxigênio, e foram relatadas, relatadas algumas doenças com envolvimento do sistema nervoso central (SNC) e da musculatura esquelética (Spiro, Prineas et al., 1970; Morgan-Hughes, 1982). 
A presença de DNA mitocondrial foi demonstrada em 1963 por Nass e Nass em embriões de galinhas (Nass, Nass, 1963), e por Schatz, em leveduras (Schatz, 1963).

A sequência do genoma mitocondrial foi elucidada em 1981 por Anderson e cols. (Anderson, Bankier et al., 1981) e nos vinte anos seguintes mais de duzentos pontos de mutações, deleções, inserções e rearranjos foram descritos (Hanna e Nelson, 1999; Jacobs, de Wert et al., 2006; Moslemi e Darin, 2007).

Em 1988, Scholte, baseado na bioquímica mitocondrial, revisou e classificou mais de 120 alterações que causavam disfunção mitocondrial (Scholte, 1988).

Desde então, há crescente identificação de defeitos da FO, os quais têm sido continuamente estudados e descritos; atualmente, constituem eles a doença metabólica hereditária mais frequente, com incidência estimada em 1:8000 (Chinnery, 2004).

Algumas das principais síndromes e doenças são referidas a seguir com relação ao ano de suas descrições.

A síndrome de Leigh foi descrita em 1951 por Denis Leigh (Leigh, 1951). Em seu relato de caso, o autor descreveu um paciente de sete meses e três semanas de vida com um desenvolvimento aparentemente normal até seis semanas antes da consulta, quando o paciente parou de chorar, começou a dormir por períodos muito longos, só despertando com estímulos, pois permanecia imóvel. Ao exame físico, o paciente aparentava ser surdo, sendo observadas atrofia óptica bilateral e moderada espasticidade nos quatro membros, não sendo obtidos os reflexos. Nos dias seguintes, houve piora do quadro com evolução do paciente para coma, hiperpirexia 
e óbito. A suspeita clínica de encefalite foi confirmada pelo estudo anatomopatológico do SNC, que evidenciou uma encefalomiopatia subaguda necrotizante.

A síndrome de Kearns-Sayre (SKS) foi descrita em 1958 por Kearns e Sayre como ptose, oftalmoplegia e pigmentação atípica da retina (retinite pigmentosa), com aspecto de "sal e pimenta" (Kearns e Sayre, 1958).

O primeiro relato de pacientes com MERRF foi descrito por Fukura e cols. em 1980. Os autores descreveram a associação em dois pacientes de mioclonia cerebelar dissinérgica, ataxia de Friedreich e miopatia mitocondrial (Fukuhara, Tokiguchi et al., 1980). Rosing e cols. descreveram uma família em que vários integrantes apresentavam esse quadro clínico e designou o termo MERRF syndrome. Considerando a variabilidade das características de hereditariedade, foi sugerida como causa uma mutação do DNA mitocondrial (Rosing, Hopkins et al., 1985). A primeira mutação específica foi demonstrada por Shoffner e col (Shoffner, Lott et al., 1990).

A MELAS foi descrita em 1984 por Pavlakis et cols. em dois pacientes com miopatia mitocondrial, encefalopatia, acidose láctica e lesões cerebrais recorrentes semelhantes a insultos vasculares (stroke like). Esses pacientes, assim como outros descritos anteriormente, apresentavam, em comum, desenvolvimento inicial normal, baixa estatura, hemiparesia, hemianopsia ou cegueira cortical e fibras vermelhas rajadas na biópsia muscular, o que levou os autores a sugerirem que se tratava de uma nova doença distinta da síndrome de Kearns-Sayre e da síndrome mioclônica 
epiléptica com fibras vermelhas rajadas. Os autores também aventaram que a transmissão seria materna (Pavlakis, Phillips et al., 1984).

\section{3- Fisiopatologia das doenças mitocondriais}

As mitocôndrias têm como principal função a produção de energia na forma de adenosina trifosfato (ATP). A função mitocondrial, através da comunicação intergênomica, é regulada pelos dois sistemas genéticos celulares: o nuclear e o mitocondrial.

A produção de ATP ocorre na cadeia respiratória através de mecanismo de fosforilação oxidativa (OXPHOS).

A cadeia respiratória ocorre na membrana interna da mitocôndria e é constituída pela série de complexos enzimáticos I, II, III, IV e V, que contém aproximadamente 70 polipeptídios, e por duas moléculas que atuam como fatores de união: a coenzima $\mathrm{Q}$ e o citocromo $\mathrm{C}$.

Como conseqüência do distúrbio da fosforilação oxidativa mitocondrial, ocorre a produção e o acúmulo de lactato, substância que, apesar de constituir aparentemente um achado universal neste grupo de doenças, não constitui um marcador específico, pois sua presença está relacionada a qualquer evento que determine interrupção da cadeia respiratória. 


\section{4- Genética das doenças mitocondriais}

As mitocôndrias apresentam um sistema genético próprio; no entanto, também dependem de proteínas codificadas no núcleo e sintetizadas nos ribossomos citoplasmáticos que, num segundo momento, são importadas. Assim, a função mitocondrial, através da comunicação intergênomica, é regulada pelos dois sistemas genéticos celulares: o nuclear e o mitocondrial.

O DNA mitocondrial (DNAmt) origina-se exclusivamente do óvulo e contém 37 genes, 13 destes codificam polipeptídios para a cadeia respiratória mitocondrial. O complexo II e os demais polipeptídios dos outros complexos são determinados por genes nucleares. Os outros 24 genes mitocondriais são necessários para a tradução de proteínas dos ribossomos mitocondriais, 22 codificam o RNA de transferência (RNAt) e 2 o RNA ribossomal (RNAr). Cada mitocôndria apresenta de duas a dez cópias de DNAmt. As mutações do DNAmt podem comprometer todos os genes ou parte deles. Podem coexistir, numa mesma célula, um DNAmt normal e um com mutação, o que é denominado de heteroplasmia. A expressão fenotípica de uma mutação do DNAmt é variável, não segue as regras da herança mendeliana e depende da proporção deste que apresenta mutação e que, assim, quantitativamente determina a alteração do metabolismo oxidativo e da demanda energética de cada tecido (Ricoy-Campo e Cabello, 2003).

As alterações do DNAmt incluem as deleções únicas, habitualmente esporádicas, as duplicações ou deleções simples e as mutações pontuais, as duas últimas de herança materna. As alterações dependentes do DNA nuclear (DNAn) têm 
herança mendeliana e incluem alterações dos genes nucleares que codificam proteínas mitocondriais, alterações na importação de proteínas mitocondriais e alterações na comunicação intergenômica (deleções múltiplas do DNAmt e depleção do DNAmt) (Ricoy-Campo e Cabello, 2003).

Mais de 200 pontos de mutação nos genes do DNA mitocondrial já foram descritos (DiMauro, 2003; Jacobs, de Wert et al., 2006) e algumas dessas mutações são explicitadas a seguir.

A síndrome de Leigh ocorre em pacientes com deficiências enzimáticas que incluem o complexo piruvato-desidrogenase e os complexos I, II e IV (citocromo C oxidadase), condições essas com hereditariedade variável, podendo ser de herança mendeliana, determinada por mutação materna, ligada ao cromossomo X, ou mesmo esporádica (Mannan, Sharma et al., 2004; Yang, Sun et al., 2006). Mutações pontuais e específicas do DNA mitocondrial foram descritas mais recentemente como T8993G, T8993C, T9176C, A8344G e A3243G (Yang, Sun et al., 2006; Zhang, Yang et al., 2007). Há também estudos demonstrando mutações no gene SURF1 (9q34) e no gene LRPPRC, responsável pela variedade franco-canadense da SL, ambas associadas à deficiência da enzima citocromo $\mathrm{C}$ oxidase (COX) (Zhu, Yao et al., 1998; Leonard e Schapira, 2000; Zhang, Yang et al., 2007). Deficiência da coenzima Q 10 e a fraqueza neurogênica com ataxia e retinite pigmentosa, relacionada ao gene MT-ATP6, também podem manifestar-se como a síndrome de Leigh (Van Maldergem, Trijbels et al., 2002).

A síndrome de Kearns-Sayre (SKS) e a síndrome de Pearson apresentam freqüentemente deleção do DNAmt (Park, Ma et al., 2004). Em 70 a 80\% dos 
pacientes com SKS, a deleçao é única e em larga escala (Carod-Artal, Lopez Gallardo et al., 2006).

A MERRF é associada a mutações no gene tRNALys; a mutação A83444G é encontrada em 80 a $90 \%$ dos pacientes, sendo também descritas outras duas mutações, T8356C e G8363A, que responderiam pela maior parte dos demais casos (Shoffner, Lott et al., 1990; DiMauro S, 2002; Mancuso, Ferraris et al., 2005).

A MELAS apresenta como mutação do DNA mitocondrial mais freqüente a substituição da guanina pela adenina no nucleotídeo (NT) 3242 no gene (mtDNA)tRNALeu(UUR), sendo esta responsável por cerca de $80 \%$ dos casos (Nakamura, Yoshinari et al., 2000).

\section{5- Neuropatologia das doenças mitocondriais}

O SNC é comprometido pela DM em padrões diversos de distribuição e severidade. As lesões mais características na substância cinzenta, embora não específicas, são: a lesão neuronal, quer por atrofia, quer por perda celular; as lesões vasculares e a necrose, representadas por cavitações, astrogliose e edema (Filosto, Tomelleri et al., 2007); na substância branca, observam-se desmielinização e degeneração espongiforme (Filosto, Tomelleri et al., 2007); a gliose também pode ocorrer (Betts, Lightowlers et al., 2004; Filosto, Tomelleri et al., 2007).

Observa-se, nessas doenças, assimetria de comprometimento das substâncias branca e cinzenta; MERRF, MELAS, e síndrome de Leigh apresentam, 
predominantemente, lesões da substância cinzenta enquanto, na síndrome de KearnsSayre, a substância branca é a mais comprometida.

A seguir são descritos alguns aspectos mais específicos de algumas das EM.

A síndrome de Leigh apresenta lesão neuronal geralmente bilateral e simétrica, preferencialmente localizada nos núcleos da base, tálamos e tronco cerebral (Filosto, Tomelleri et al., 2007).

A síndrome de Kearn-Sayre caracteriza-se por degeneração espongiforme da substância branca e do tronco cerebral (Betts, Lightowlers et al., 2004).

A MERRF cursa com degeneração neuronal predominantemente em estruturas subcorticais, como os núcleos denteados, o tronco cerebral e o córtex cerebelar (Betts, Lightowlers et al., 2004).

A MELAS apresenta múltiplas lesões semelhantes a infartos, porém sem respeitar os territórios vasculares; as regiões mais comprometidas são os córtices occipital, parietal and temporal. A substância cinzenta profunda, o cerebelo e o tronco cerebral também apresentam perda neuronal (Betts, Lightowlers et al., 2004). No córtex cerebral, podem ser observadas alterações espongiformes, proliferação astrocítica e capilar; os neurônio são relativamente poupados (Sue, Crimmins et al., 1998). 


\section{6- Quadro clínico das doenças mitocondriais}

As primeiras manifestações clínicas deste grupo de doenças, que ocorre durante a infância ou em adultos jovens, são amplas e variáveis, porém o encéfalo e os músculos são os tecidos mais freqüentemente afetados, devido ao fato de sua produção energética depender da fosforilação oxidativa mitocondrial (Hanna and Nelson 1999). Assim, o quadro clínico mais freqüente é de fraqueza muscular associada a alterações neurológicas como convulsões, episódios "stroke-like", retardo do desenvolvimento na infância, demência na vida adulta, ataxia, neuropatia óptica, retinopatia, deficiência auditiva neurossensorial e neuropatia periférica (Lin, Crawford et al., 2003). Nota-se também fraca correlação entre genótipo e fenótipo.

A seguir são descritas algumas das principais doenças e síndromes com referência aos sinais e sintomas mais relacionados e frequentes, apesar de, como descrito anteriormente, o quadro clínico ser bastante diversificado.

A síndrome de Leigh tem apresentação clínica variável e cursa com crises convulsivas, retardo psicomotor, atrofia óptica, hipotonia, letargia, vômitos, ataxia, tremor, sinais piramidais, irritabilidade, nistagmo, oftalmoplegia e alterações respiratórias. Pincus apresentou uma série de 78 pacientes e descreveu dois grupos: um com início da doença antes dos 12 meses de vida e outro, com início após 18 meses de vida; esse autor observou, também, que a apresentação clínica é inconstante. No primeiro grupo, predominavam retardo psicomotor, vômitos e perda de peso; no segundo, eram mais frequentes distúrbios de movimento, coma e nistagmo (Pincus 1972). A fraqueza neurogênica com ataxia e retinite pigmentosa 
(da sigla em inglês: NARP) também pode se manifestar clinicamente como a síndrome de Leigh; outros sintomas incluem retardo no desenvolvimento, neuropatia sensorial, ataxia e fraqueza muscular neurogênica proximal além de sintomas visuais decorrentes da retinite pigmentar (Keranen e Kuusisto, 2006).

A síndrome de Kearns-Sayre (SKS) cursa com ptose, oftalmoplegia e pigmentação atípica da retina (retinite pigmentosa), com aspecto de "sal e pimenta". A síndrome de Pearson é caracterizada por anemia hipocelular e deficiência exócrina do pâncreas, podendo evoluir para a SKS. Os pacientes podem apresentar também alterações neurológicas como ataxia e demência, bem como alterações endócrinas diabetes mellitus, hiperaldosteronismo e hipoparatireoidismo. Geralmente, desenvolvem defeitos de condução cardíaca com conseqüentes síncopes e morte súbita (Park, Ma et al., 2004).

O início do quadro clínico na MERRF se dá na vida adulta (Barkovich et al., 2005). Apresenta-se como epilepsia caracterizada por convulsões mioclônicas que podem ou não se generalizar. Outros sintomas são demência, lipomatose múltipla simétrica, déficits do trato córtico-espinal, surdez, neuropatia periférica, cardiomiopatia e disfunção tubular renal (von Kleist-Retzow, Schauseil-Zipf et al. 2003).

O início da MELAS pode ser em qualquer idade, mas, geralmente, é por volta da segunda década da vida. Cursa com encefalopatia - frequentemente associada a convulsões parciais de difícil controle medicamentoso (Valanne, Ketonen et al., 1998) - demência progressiva, episódios "stroke-like" recorrentes, cefaléia pulsátil e 
perda auditiva neurossensorial. Baixa estatura e diabetes mellitus também são freqüentes (von Kleist-Retzow, Schauseil-Zipf et al., 2003).

\section{7- Diagnóstico das doenças mitocondriais}

O diagnóstico das DM é feito através de um conjunto de estudos que incluem inicialmente uma avaliação clínica minuciosa seguida de exames subsidiários como a análise bioquímica do sangue, do LCR, da urina, o estudo por RM, a biópsia muscular e a análise genética.

A análise bioquímica do plasma caracterizando um nível de lactato acima de 2,1 $\mathrm{mmol} / \mathrm{L}$ ou $19 \mathrm{mg} / \mathrm{dL}$ é considerada suspeita (Zschocke e Hoffmann, 2004) assim como uma relação lactato/piruvato acima de 25:1 (Filosto, Tomelleri et al., 2007); entretanto, um valor normal não exclui uma doença mitocondrial (Zschocke e Hoffmann, 2004). O nível de creatina quinase pode ser normal ou moderadamente alto, exceto em pacientes com miopatias relacionadas à depleção do DNA mitocondrial, quando essa mensuração geralmente é superior a 1000 UI (DiMauro, Bonilla et al., 1999). Outra alteração sanguínea que pode ser observada em alguns pacientes é o aumento da alanina (Morava, Hogeveen et al., 2006).

A análise bioquímica do LCR pode evidenciar um nível normal ou elevado de lactato (considerando-se, para pacientes pediátricos, aumentado um valor superior a $1,8 \mathrm{mmol} / \mathrm{L}$ ou $16 \mathrm{mg} / \mathrm{dL}$ ) (Benoist, Alberti et al., 2003; Zschocke e Hoffmann, 2004), piruvato, proteínas e células (Finsterer, 2006). Bandas oligoclonais podem ser 
detectadas e estão, provavelmente, relacionadas à resposta imune frente à detecção de proteínas alteradas pelas mutações genéticas (Finsterer, 2006).

A análise bioquímica da urina pode evidenciar um nível elevado de lactato e de intermediários do ciclo de Krebs (Barshop 2004; Zschocke e Hoffmann, 2004).

Diversas outras alterações liquóricas e urinárias relacionadas especificamente a uma das doenças ou a uma das síndromes pertencentes as DM podem ser caracterizadas; a descrição detalhada e específica está, no entanto, além do escopo deste trabalho.

A biópsia muscular pode demonstrar, na coloração tricrômica de Gomori modificada, as fibras vermelhas rajadas com proliferação patológica de mitocôndrias estruturalmente alteradas; reações de succinato desidrogenase evidenciam acúmulo difuso ou subsarcolemal; coloração para citocromo c oxidase (COX) demonstram fibras COX negativas (Filosto, Tomelleri et al., 2007).

As alterações genéticas, quando conhecidas, são realizadas por testes cujos genes relacionados foram referidos no item 3.3 (Genética das doenças mitocondriais). Os exames realizados são vários e incluem "Southern blot" para pesquisa de rearranjos, reação de cadeia de polimerase (PCR) e sequenciamento genético direto ou cromatografia líquida de alta performance desnaturante (DHPLC) (Filosto, Tomelleri et al., 2007).

Os aspectos observados através do estudo por RM do SNC serão detalhados no item específico, 3.8 (RM nas doenças mitocondriais). 
A espectroscopia por RM de fósforo também pode ser utilizada para avaliar a relação fosfocreatina/fosfato inorgânico na musculatura esquelética durante $o$ repouso, o exercício e a fase de recuperação (Gillis e Kaye, 2002). Os pacientes com DM apresentam um valor dessa relação; entre metabólitos, baixa em repouso, muito reduzido ao esforço e com recuperação lenta (Filosto, Tomelleri et al., 2007).

\section{8- Ressonância magnética nas doenças mitocondriais}

A RM é um método altamente sensível para a caracterização das alterações do encéfalo e constitui o método de imagem de escolha para o estudo deste grupo de doenças.

As EM têm expressão variável pela RM. Muito pacientes apresentam achados inespecíficos como focos de hipersinal em T2 na substância branca ou apenas retardo da mielinização. Um aspecto de imagem bastante sugestivo deste grupo de doenças é o comprometimento da substância cinzenta profunda (núcleos da base), associado a alterações da substância branca.

A seguir são descritas algumas das principais doenças e síndromes com aspectos mais típicos na RM.

A síndrome de Leigh é causada por diferentes defeitos genéticos ainda não totalmente estabelecidos. Assim, o aspecto de imagens também apresenta variações. Classicamente, apresenta, como achados de RM, lesões com hipossinal em T1 e hipersinal em T2 no corpo estriado e retardo da mielinização. A ERM demonstra 
redução do $\mathrm{N}$-acetil aspartato (Naa) e presença do pico de lactato. Outro padrão de imagem nesta doença é o de comprometimento dos núcleos subtalâmicos, bulbo, ponte, pedúnculos cerebelares inferiores, olivas e substância cinzenta periaquedutal (Barkovich 2005).

A Síndrome de Kearns-Sayre pode, inicialmente, apresentar aspecto normal à RM. Com o decorrer da doença, surgem focos de hipersinal nas seqüências ponderadas em T2 na substância branca subcortical, caracteristicamente com envolvimento das fibras em "U", mas poupando a região periventricular. Posteriormente, há comprometimento dos núcleos da base, tálamos e mesencéfalo. A ERM demonstra redução do Naa e presença do pico de lactato (Barkovich, Good et al., 1993).

A MERRF demonstra atrofia cerebral e cerebelar, focos de hipersinal em T2 e FLAIR na substância branca, atrofia e calcificações palidais, lesões em tronco e medula espinhal e acentuada tortuosidade dos vasos cerebrais (Lexa, 1996; Ito, Shirai et al., 2008).

A MELAS apresenta classicamente comprometimento das substâncias cinzenta e branca inicialmente dos lobos parietal e occipital, cujo aspecto à RM é semelhante ao de eventos vasculares isquêmicos, diferenciando-se desses por não respeitar um território vascular específico; a substância cinzenta profunda também pode ser acometida (Oppenheim, Galanaud et al., 2000; AJ 2005; Barkovich et al., 2005). Na fase aguda, essas lesões apresentam-se edematosas e com sinal alto em T2 e FLAIR nos estudos de RM (Abe, Inui et al., 1990; Matthews, Tampieri et al., 1991; Barkovich, Good et al., 1993; Ohshita, Oka et al., 2000). A sequência de difusão 
pode mostrar hipersinal nas áreas comprometidas, porém com valores normais ou com aumento dos coeficientes de difusão aparente (CDA), aspecto esse que pode auxiliar na diferenciação das lesões decorrentes da MELAS daquelas relacionadas a eventos vasculares isquêmicos (Oppenheim, Galanaud et al., 2000; Yonemura, Hasegawa et al., 2001). A evolução pode mostrar a resolução das mesmas ou o aspecto seqüelar caracterizado por atrofia cortical. Como a doença evolui em surtos, estas lesões são descritas como migratórias, já que o local comprometido é variável (Rosen, Phillips et al., 1990; Kim, Kim et al., 1996). A ERM pode evidenciar presença do pico de lactato tanto nas áreas com alteração nas seqüências ponderadas em T2 como nas que apresentam sinal habitual (Barkovich, Good et al., 1993; AJ, 2005).

Em resumo, considerando este grupo de doenças, pode-se dizer que os padrões de imagem por RM nas EM têm apresentação bastante variável, incluindo desde exames com aspecto normal a exames com padrões alterados com aspecto degenerativo, similar à leucomalácia periventricular, à esclerose múltipla e à leucodistrofia ou alterações em núcleos da base, tronco cerebral e cerebelo. Outras alterações também observadas são lesões stroke-like, alterações similares à encefalomielite aguda disseminada, alterações de sinal no trato óptico e hipófise de dimensões reduzidas (Palasis, 2001). 


\section{9- Espectroscopia de prótons por ressonância magnética}

A espectroscopia de prótons por ressonância magnética (ERM) é uma ferramenta de diagnóstico não invasiva que permite o estudo in vivo de metabólitos. Surgiu no início da década de 70, concomitantemente com as imagens estruturais por RM; seu desenvolvimento é atribuído a Lautenbun e Damadian que desenvolveram seus trabalhos simultanemente, mas de modo independente. Em 1971, Damadian, físico do Downstate Medical Center no Brooklyn, New York, Estados Unidos, interessado na dinâmica celular, estudou as propriedades de relaxamento de tecidos sãos de ratos e neoplasias benignas e malignas humanas (Damadian, 1971; Hendee 1989; Macchia, Termine et al., 2007). Lautenbun, químico da Universidade de Nova York, Estados Unidos, produziu a primeira imagem reconstruída a partir do sinal de RM de dois tubos capilares preenchidos por água, o que denominou zegmatografia em 1973 (Hendee, 1989; Lauterbur, 1989).

A partir de então, houve o desenvovimento de equipamentos de RM para uso clínico. Muitos desses equipamentos, além de fornecer as imagens morfológicas, eram aptos a realizar a ERM; sua análise, contudo, era dificultada em função da necessidade de processamento dos dados após sua obtenção.

O passo seguinte foi o desenvolvimento de uma sequência de ERM automatizada e rápida, a qual foi aprovada em 1995 pelo FDA (Food and Drug Administration) para uso nos Estados Unidos. Houve, assim, um grande interesse na sua utilização, que cresceu exponencialmente na prática clínica, sendo incorporada 
aos protocolos de rotina de exames de diagnóstico por imagem do encéfalo utilizando a RM (Ross e Bluml, 2001).

O hidrogênio é o átomo mais estudado na prática clínica pela ERM por ser abundante no organismo, por sua alta sensibilidade à RM em relação a outros núcleos e pelo fato de utilizar a mesma bobina empregada na obtenção das imagens estruturais rotineiras (Castillo, Kwock et al., 1996). Outros átomos que podem ser estudados pela ERM e com interesse biológico são o lítio, o carbono, o nitrogênio, o flúor, o sódio, o alumínio, o fósforo, o cloro, o potássio, o manganês e o cobalto (McClure, Kanfer et al., 1995).

$\mathrm{Na}$ ERM, são analisadas amostras tridimensionais denominadas de volume de interesse (VOI). Assim, o VOI deve ser posicionado de forma a conter a maior amostra do tecido a ser estudado.

O mecanismo de formação de imagem através da RM consiste em aplicar, por alguns microssegundos, um pulso de radiofrequência (PRF) específico para o elemento químico escolhido. Esse evento ocorre dentro de um ambiente no qual o material estudado, seja um paciente, seja uma amostra, está submetido a um forte campo magnético que determina o alinhamento de todos os seus átomos, incluindo os do elemento químico escolhido, paralelo ao próprio campo. Durante o PRF, há o desalinhamento do vetor total de magnetização, que consiste na somatória de todos os vetores determinados por todos os átomos do elemento químico escolhido. Desligado o PRF, é gerado um pequeno sinal elétrico, denominado na língua inglesa de free induction decay (FID), decorrente do realinhamento ao campo magnético. Esse sinal elétrico é detectado pela bobina e após várias repetições desse mecanismo, 
através da transformada de Fourier, obtém-se um gráfico, que é a apresentação da espectroscopia.

O eixo horizontal do gráfico demonstra a variação da frequência de ressonância de cada metabólito, denominada de desvio químico, a qual é específica para cada substância e expressa em partes por milhão (ppm); essa unidade é independente da magnitude do campo magnético utilizado (Jacobs, Ibrahim et al., 2007). O eixo vertical avalia a amplitude de cada metabólito.

A água é a molécula mais abundante nos tecidos humanos, assim, é necessária a supressão de seu sinal, pois, caso contrário, seu pico no espectro seria tão preponderante que os demais picos seriam pouco distinguíveis da linha de base do gráfico. Para tanto, utilizam-se pulsos seletivos de radiofrequência, denominados de CHESS (chemical shift selective), antes da realização da seqüência de espectroscopia propriamente dita. Esses PRF têm largura estreita e são centralizados sobre a freqüência de ressonância dos prótons da água, saturando-os e anulando o seu sinal (Kwock, 1998).

A homogeneização do campo magnético no interior do VOI é outro passo para a obtenção de uma boa ERM. Para isso, são realizados ajustes, denominados em inglês de shimming, procedimentos geralmente automatizados. A heterogeneidade do campo magnético no interior do VOI ou próxima a este é indesejável, pois determina redução da relação sinal/ruído e diferentes desvios químicos para um mesmo metabólito no interior do VOI, cujo efeito final é o alargamento dos picos. Dessa forma, com os picos alargados, há sobreposição entre picos diferentes e dificuldades maiores para a quantificação dos metabólitos a serem analisados. 
A ERM pode utilizar um VOI único, denominado em inglês de single voxel, ou múltiplos volumes de interesse adquiridos simultaneamente, em inglês, multivoxel. Enquanto o VOI único estuda uma só amostra, que é colocada na região de interesse, a aquisição simultânea de múltiplos VOIs realiza várias amostragens simultaneamente, numa mesma região previamente selecionada.

As duas técnicas mais utilizadas para a aquisição de ERM são o modo de aquisição baseado em ecos estimulados e a espectroscopia com resolução pontual, ambas mais conhecidas pelas siglas em inglês STEAM (stimulated echo acquisition mode) e PRESS (point resolved spectroscopy), respectivamente. Há vantagens e desvantagens em ambas (Castillo, Kwock et al., 1996; Kwock, 1998; Danielsen e Ross, 1999; Ross e Bluml, 2001).

Atualmente tanto a técnica STEAM quanto a PRESS permitem detectar metabólitos com tempo de eco (TE) curto e longo.

A técnica STEAM apresenta como vantagem uma supressão de água mais efetiva e sem necessidade de aumento do tempo total de aquisição da seqüência, pois, durante o tempo de mistura (TM), que consiste em um intervalo durante a seqüência, é possível realizar pulsos adicionais de saturação dos prótons da água, além daqueles aplicados antes do início da seqüência. Entretanto, a técnica STEAM é mais sensível à movimentação do paciente.

A técnica PRESS, baseada numa variação da seqüência clássica de eco de spins da RM convencional, apresenta maior relação sinal/ruído e é menos sensível à movimentação do paciente (Kwock, 1998). 
Os estudos com VOI único podem utilizar qualquer uma das técnicas, mas a aquisição simultânea de múltiplos VOIs geralmente utiliza TE longo na maioria dos aparelhos em uso comercial.

Os principais metabólitos analisáveis pela ERM são $\mathrm{N}$-acetil aspartato, creatina, colina, mio-inositol, lactato (Lac), lipídios e glutamina/glutamato (Kwock, 1998).

O N-acetil aspartato é um metabólito exclusivo de neurônios e oligodendrócitos imaturos, não sendo caracterizado em outros tecidos que não o encefálico (Simmons, Frondoza et al., 1991; Urenjak, Williams et al., 1992). Existe no cérebro numa concentração máxima de até $12 \mathrm{mmol} / \mathrm{L}$ (Miyake e Kakimoto, 1981; Miyake, Kakimoto et al., 1981; Urenjak, Williams et al., 1992; Bluml, 1999; Pan e Takahashi, 2005), o que o torna uma das moléculas em maior concentração no encéfalo, sendo considerado um marcador da saúde neuronal bem como de sua viabilidade e de sua população (Moffett, Ross et al., 2007). Entretanto, a compreensão de sua funções neuroquímica e metabólica continuam a ser investigadas e permanecem controvertidas, apesar de ser estudado há cerca de cinco décadas (Moffett, Ross et al., 2007). O Naa é sintetizado na mitocôndria a partir do aspartato e da acetiyl-coenzima A pela enzima L- aspartato N-acetiltransferase (Patel e Clark, 1979; Truckenmiller, Namboodiri et al., 1985); é transportado do neurônio para o oligodendrócito onde, no citoplasma, é degradado pela enzima aspartoacilase para a síntese de ácidos graxos e esteróides, os quais serão utilizados na confecção da bainha de mielina (Baslow e Guilfoyle, 2006). Após o processo de mielinização, o Naa permanece envolvido na manutenção da mielina e possivelmente também cumpre papel bioenergético na mitocôndria neuronal (Tallan, 1957; Patel e Clark, 
1979; Madhavarao, Chinopoulos et al., 2003). A hipótese aventada é de que a acetilação do aspartato pode facilitar sua remoção da mitocôndria e, assim, favoreceria a conversão de glutamato para alfa cetoglutarato, o qual integra a produção de energia através de sua entrada no ciclo do ácido tricarboxílico (Madhavarao, Moffett et al., 2004). Há evidências de que o Naa seja um precursor direto na síntese enzimática do $\mathrm{N}$-acetilaspartilglutamato, o qual constitui o peptídeo em maior concentação no neurônio e específico desta célula (Moffett, Ross et al., 2007). Outras possíveis funções do Naa seriam a osmorregulação celular e a sinalização entre axônio e glia (Taylor, Davies et al., 1994; Baslow e Guilfoyle, 2006). Moffett e cols. (Moffett, Ross et al., 2007) também sugerem que o Naa esteja envolvido no balanço do nitrogênio cerebral. Sua concentração diminui de maneira inespecífica nas doenças em que há perda neuronal e/ou axonal já que, no neurônio, o Naa está presente no corpo celular, no axônio e nos dendritos (Simmons, Frondoza et al., 1991); também pode ser observada a redução de seu pico em disfunções reversíveis do neurônio ou da mitocôndria (De Stefano, Matthews et al. 1995; Gasparovic, Arfai et al. 2001; Demougeot, Marie et al., 2004; Moffett, Ross et al., 2007). A concentração de Naa se apresenta aumentada quase que exclusivamente na doença de Canavan, uma condição genética hereditária e rara em que o excesso desta substância determina efeitos deletérios às células. Relatos esporádicos referem o aumento do Naa nos núcleos da base de pacientes pediátricos diagnosticados com anemia falciforme e de ratos medicados com haloperidol (Harte, Bachus et al., 2005; Steen e Ogg, 2005). É detectado através da ressonância de seu grupo N-acetil metil e apresenta contribuições de outros grupos $\mathrm{N}$-acetil menos importantes. Em condições normais, é o maior pico do espectro e se encontra em 2,02 e 2,6 ppm (De Graaf, 
1998; Wang e Zimmerman, 1998; Danielsen e Ross, 1999); pode ser estudado com TE curto ou longo.

A creatina é um marcador dos sistemas de produção de energia nas células do SNC, pois funciona como reservatório de fosfatos de alta energia e como um tampão para os reservatórios de ADP-ATP, refletindo, assim, a integridade dos sistemas energéticos. É relativamente estável e utilizada como denominador para a realização das razões entre os metabólitos. O pico da creatina contém contribuições da creatina, da fosfocreatina e, em menor quantidade, do ácido $\gamma$-aminobutírico, da lisina e da glutationa. O pico principal da creatina está localizado em 3,03 ppm, havendo também um pico adicional em 3,93 ppm (De Graaf, 1998; Kwock, 1998; Wang e Zimmerman, 1998; Danielsen e Ross, 1999); pode ser estudada com TE curto ou longo.

A colina é um precursor da acetilcolina e da fosfatidilcolina estando, assim, envolvida na síntese e na degradação de fosfolipídios das membranas celulares, refletindo o turnover dessas; portanto, está aumentada em processos em que existe hipercelularidade, como, por exemplo, em neoplasias, tanto primárias quanto secundárias do SNC, e em lesões desmielinizantes. O pico da colina mede o total de colina móvel; inclui, portanto, colina livre, acetilcolina e fosfatidilcolina, abrangendo sua substância precursora e seu produto de degradação, que são, respectivamente, a fosfocolina e a glicerofosfocolina. Este pico está localizado em 3,22 ppm (De Graaf, 1998; Kwock, 1998; Wang e Zimmerman, 1998; Danielsen e Ross, 1999); pode ser estudada com TE curto ou longo. 
O mio-inositol é um metabólito marcador de células gliais, tem função relacionada ao controle da osmolaridade, ou regulação do volume celular; é um mensageiro intracelular e um agente desintoxicante no cérebro. Está aumentado em processos que cursam com gliose e em tumores gliais bem diferenciados (Castillo, Smith et al., 2000). O mio-inositol é também um produto da degradação da mielina. O pico do mio-inositol está localizado em 3,56 e 4,0 ppm (Zimmerman e Wang, 1997; Kwock, 1998; Wang e Zimmerman, 1998; Danielsen e Ross, 1999). Para ser detectado, a ERM deve ser realizada com TE curto.

O lactato está aumentado quando há falha na respiração oxidativa com aumento do metabolismo anaeróbio da glicose e também no catabolismo de carboidratos; em situações normais, está ausente ou presente em pequenas quantidades. Este pico tem uma configuração característica, constituída, na verdade, por dois picos distintos sobrepostos parcialmente (doublet) devido a interações entre prótons adjacentes (acoplamento de spins). Como particularidade, apresenta inversão de seu pico com TE longo, de 136-144 ms. Está localizado em 1,33 ppm, havendo também um segundo pico em 4,1 ppm o qual, por estar muito próximo ao pico da água, geralmente é suprimido (Castillo, Kwock et al., 1998; Wang e Zimmerman, 1998; Danielsen e Ross, 1999); pode ser estudado com TE curto ou longo; entretanto, com TE curto, pode haver uma sobreposição com o pico de lipídios.

Os lipídios não são identificados em quantidades significativas em condições normais, mas são encontrados em lesões que contêm necrose, por exemplo, em tumores de alto grau. A necrose, a partir da quebra de grandes moléculas, produz lipídios menores, detectáveis pela espectroscopia. Os picos de lipídios estão localizados em 0,$80 ; 1,20$ (que pode se sobrepor ao pico de lactato); 1,50 e 6,00 ppm, 
compostos pela ressonância dos prótons de grupamentos metil, metileno, alélico e vinil, insaturados (Zimmerman e Wang, 1997; Castillo, Kwock et al., 1998; Danielsen e Ross, 1999). A sua detecção deve ser analisada cuidadosamente, pois seu aparecimento pode ser decorrente de contaminação de gordura do subcutâneo dentro do VOI; a proximidade de seu pico com o do lactato também requer análise minuciosa para sequências com TE curto. Para sua detecção, a ERM deve ser realizada com TE curto.

O glutamato é o principal neurotransmissor excitatório; a glutamina tem um papel na destoxificação e na regulação do glutamato, seu precursor. Os picos de glutamato/glutamina (Glx) são identificados sobrepostos, devido a acoplamento de spins bastante importante, entre 2,05 e 2,50 ppm. Necessita de TE curto para ser estudado.

Os pacientes com EM podem apresentar ERM normal ou alterada, dependendo do grau do comprometimento do SNC. Os achados que podem ser observados nesses pacientes são inespecíficos, tais como, redução de N-Acetil aspartato (Naa) e colina (Co), implicando perda ou disfunção neuronal, aumento de glutamato (Glx), indicando excesso de neurotransmissores excitatórios e presença do pico de lactato, configurando um distúrbio metabólico agudo (Barkovich, Good et al., 1993). O pico do lactato, apesar de não ser uma alteração específica destas doenças, associado com os achados nas imagens convencionais (alterações de núcleos da base e comprometimento do parênquima que não segue a distribuição de um território vascular), faz com que esta possibilidade diagnóstica seja aventada. E este achado pode ser mais persistente na ERM do que no LCR, posto que esta substância é retirada do parênquima para o LCR e, posteriormente, deste para a 
circulação sistêmica (Inao, Marmarou et al. 1988). Assim a RM é um método útil na investigação diagnóstica e, também, no seguimento destes pacientes (Lin, Crawford et al., 2003). Outra possível aplicação da ERM é a de monitorização da resposta destas doenças ao tratamento, pois áreas de parênquima com morfologia e sinal preservados podem apresentar alterações funcionais caracterizadas pela presença de lactato (Krageloh-Mann, Grodd et al., 1993; Zimmerman e Wang, 1997; Wang e Zimmerman, 1998). 
4 - Casuística e Métodos

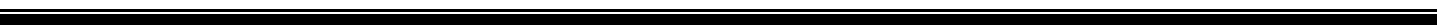




\section{1- Casuística}

Este foi um estudo prospectivo baseado nas análises de ERM realizadas no setor de Ressonância Magnética do Hospital das Clínicas da Faculdade de Medicina da Universidade de São Paulo (HCFMUSP), compreendendo o período de novembro de 2005 a novembro de 2006; envolveu 22 pacientes provenientes do ambulatório de Neuropediatria da Clínica Neurológica do HCFMUSP.

Foram considerados critérios de inclusão no estudo: pacientes com suspeita de encefalopatia mitocondrial e que aceitaram participar do estudo com a assinatura do termo de consentimento informado pelo paciente ou por seu responsável legal.

Foram considerados como critérios de exclusão: impossibilidade de obtenção de ERM com qualidade para diagnóstico e/ou a impossibilidade de pósprocessamento das espectroscopias obtidas. Um dos pacientes da casuística foi excluído de acordo com estes critérios (por uso de aparelho ortodôntico que impossibilitou a aquisição da ERM); portanto, 21 pacientes fazem parte deste trabalho.

Os pacientes apresentavam idades variando entre 9 meses e 20 anos (média: 6 anos e 5 meses, mediana: 4 anos e 10 meses). Quanto à distribuição dos pacientes por sexo, 8 eram do sexo masculino (38\%), 13, do sexo feminino (62\%), com relação M:F de 0,61:1 [Gráfico 1]. O conjunto dos pacientes, com seus registros no HCFMUSP e datas de realização dos exames, pode ser observado no ANEXO 1. 


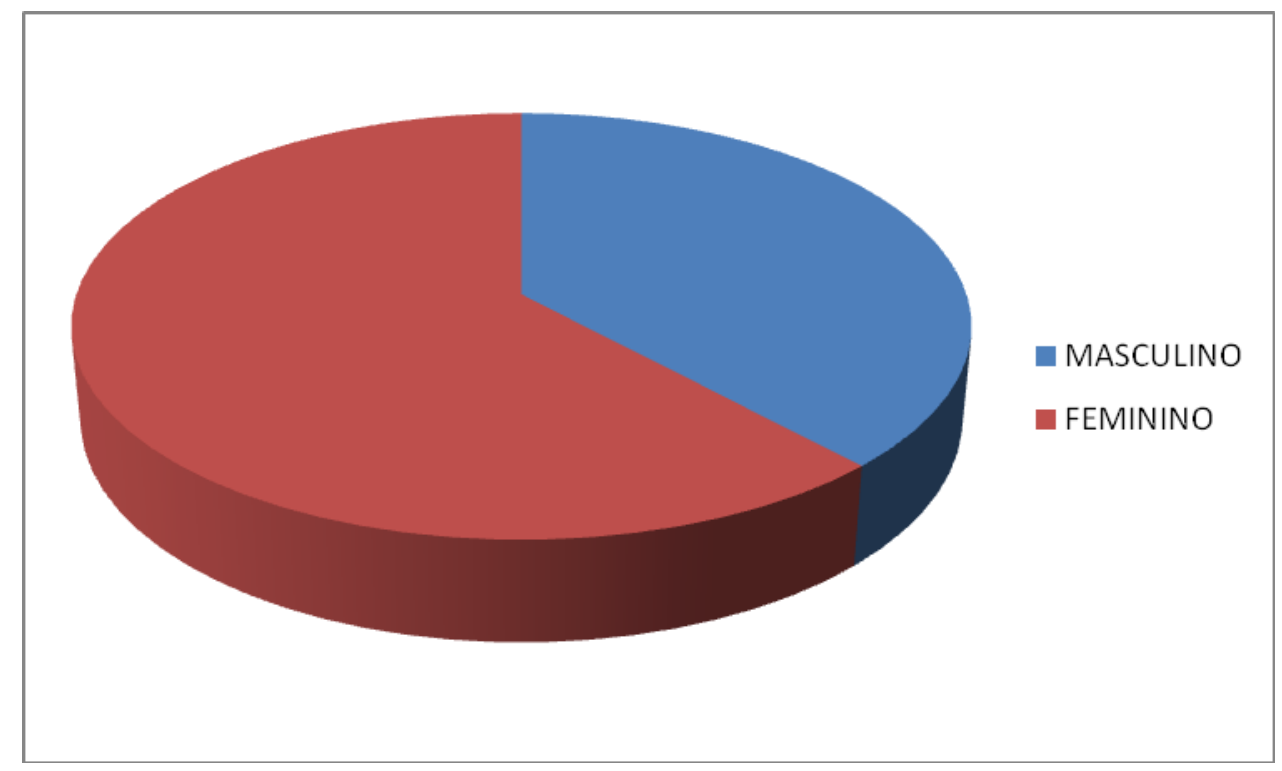

GRÁFICO 1 - Distribuição dos pacientes por sexo

Os pacientes realizaram exame após esclarecimento e assinatura do termo de consentimento informado. O protocolo de estudo recebeu aprovação da Comissão de Ética do HCFMUSP [ANEXO 2].

\section{2- Métodos}

\section{Avaliação clínica e seleção de pacientes}

A hipótese diagnóstica de EM foi feita a partir da análise dos sintomas e sinais clínicos.

Para a seleção de pacientes, os seguintes passos foram pesquisados: os antecedentes familiares como consangüinidade entre os pais, parentes com doenças 
genéticas ou com quadro clínico semelhante ao do paciente, além da evolução do desenvolvimento psicomotor e início da idade dos sintomas do paciente. Também foi averiguada a ocorrência de crise epiléptica e cefaléia.

Todos os pacientes foram submetidos à avaliação neurológica prévia à realização dos exames de IRM e ERM, por pelos mesmos dois examinadores de uma equipe de três neuropediatras (ALC, EKL e FK). O exame físico geral incluiu análise pondero-estatural, do perímetro cefálico, cor de olhos e pele além de avaliações cardíaca, respiratória, renal, hepática, intestinal, hematológica e endocrinológica. O exame clínico neurológico avaliou deficiências mental, auditiva e visual, tônus muscular, miopatias, neuropatias, mielopatias, ataxias e movimentos involuntários.

Outros exames complementares incluíram eletroencefalograma e eletroneuromiografia.

\section{Análise bioquímica do LCR}

A amostra de LCR para dosagem do lactato foi obtida imediatamente após a realização do exame de RM; para tal foi realizada a punção lombar e o material coletado em tubo de ensaio estéril o qual foi mantido refrigerado durante seu encaminhamento ao laboratório, seguindo as orientações estabelecidas no manual de exames do laboratório central do Hospital das Clínicas da FMUSP, o qual se encontra disponível online (http://www.dlc.honet.usp.br/mexames/me action mostrar exame.asp?id=302). A mensuração dessa substância foi obtida através de procedimento enzimático 
colorimétrico com lactato oxidase e 4-aminoantipyrina, imediatamente após a coleta do material. Através deste método, o lactato é oxidado para piruvato e peróxido de hidrogênio pela lactato oxidase. Na presença de peroxidase, o peróxido de hidrogênio reage com 2, 4, 6-tribromo-3 ácidohidroxibenzóico e 4-aminoantipirina colorindo com vermelho quinoneimina. Assim, a coloração é intensificada pela formação do vermelho quinoneimina o qual é diretamente proporcional à concentração de lactato. Este é determinado através da medida crescente em absorbância a $552 \mathrm{~nm}$. Foi considerado aumentado o lactato liquórico, quando o valor era superior a $16 \mathrm{mg} / \mathrm{dL}$ ou 1,8 $\mathrm{mmol} / \mathrm{L}$, sendo utilizado o valor de conversão $0,11(\mathrm{mmol} / \mathrm{L}=\mathrm{md} / \mathrm{dL}$ x 0,11$)$ (Zschocke and Hoffmann 2004).

\section{Análise bioquímica do sangue}

A amostra de sangue para dosagem do lactato também foi obtida imediatamente após a realização do exame de RM, seguindo as orientações do manual de exames do Hospital das Clínicas da FMUSP, previamente citado (http://www.dlc.hcnet.usp.br/mexames/me_action_mostrar_exame.asp?id=301); com os pacientes em repouso, foi realizada, para tanto, a cateterização de uma veia periférica. O sangue foi coletado em tubo de ensaio contendo anticoagulante (fluoreto de sódio e oxalato de potássio) e imediatamente encaminhamento ao laboratório, tendo sido mantido refrigerado durante esse período. A mensuração dessa substância foi obtida através de procedimento enzimático colorimétrico com lactato oxidase e 4-aminoantipirina, como descrito anteriormente para a dosagem 
desta substância no líquor. Foi considerado aumentado o lactato sérico, quando o valor era superior a $19 \mathrm{mg} / \mathrm{dL}$ ou $2,1 \mathrm{mmol} / \mathrm{L}$, sendo utilizado o valor de conversão 0,11 (mmol/L $=\mathrm{md} / \mathrm{dL} * 0,11)($ Zschocke and Hoffmann 2004).

\section{Equipamento de ressonância magnética}

Os exames foram realizados em aparelho de RM com 1,5 Tesla, da marca GE - modelo Signa Horizon LX 8.2 (General Eletric, Sistemas Médicos, Milwaukee, Wisconsin, EUA), com gradiente de $33 \mathrm{mT} / \mathrm{m}$ de intensidade, em bobina de quadratura para o estudo do crânio.

\section{Imagens de ressonância magnética}

O protocolo de aquisição das imagens de ressonância magnética do crânio, em todos os pacientes, foi constituído pelas seguintes seqüências: eco de spins (ES) nos planos sagital e axial pesadas em $\mathrm{T} 1$, eco de spins rápido (ESR) no plano axial pesada em T2, ponderada em FLAIR no plano axial e ES pesada em T2 no plano coronal [Tabela 1]. Entre os pacientes, 18 foram submetidos à sedação para realização do exame.

As seqüências foram obtidas com campo de visão de $18 \times 24 \mathrm{~cm}$ ou de $24 \times$ $24 \mathrm{~cm}$. Na seqüência ESR, o comprimento do trem de ecos variou entre 12 e 22 . 
O tempo médio total do exame destes pacientes, incluindo a ERM, foi de cerca de 50 minutos.

TABELA 1 - Parâmetros técnicos de rm das seqüências utilizadas

\begin{tabular}{|c|c|c|c|c|c|c|}
\hline Séries & $\begin{array}{l}\mathrm{TR} \\
(\mathrm{ms})\end{array}$ & $\begin{array}{l}\mathrm{TE} \\
(\mathrm{ms})\end{array}$ & $\begin{array}{l}\mathrm{TI} \\
(\mathrm{ms})\end{array}$ & $\begin{array}{c}\text { Espessura/ intervalo } \\
(\mathrm{mm})\end{array}$ & Matriz & NEX \\
\hline Difusão & $8000-11000$ & $90-115$ & & 5,0 & $256 \times 256$ & 1 \\
\hline $\begin{array}{l}\text { Sagital T1 } \\
\text { ES }\end{array}$ & 400 & $9-14$ & - & $5,0 / 1-1,5$ & $\begin{array}{l}256 \times 256 \\
512 \times 512\end{array}$ & 1 \\
\hline $\begin{array}{l}\text { Axial T1 } \\
\text { ES }\end{array}$ & 500 & 9 & - & $5,0 / 1,0-1,5$ & $512 \times 512$ & 1 \\
\hline $\begin{array}{l}\text { Axial T2 } \\
\text { ESR }\end{array}$ & 5100 & $102-106$ & - & $4,5-5,0 / 1,0-1,5$ & $512 \times 512$ & 2 \\
\hline $\begin{array}{l}\text { Axial } \\
\text { FLAIR }\end{array}$ & 10002 & 104-109 & $2100-2300$ & $5,0 / 1,0-1,5$ & $512 \times 512$ & 1 \\
\hline $\begin{array}{l}\text { Coronal } \\
\text { T2 GRE }\end{array}$ & $450-500$ & 15 & - & $4,5-5,0 / 1,0-1,5$ & $256 \times 256$ & \\
\hline
\end{tabular}

Nota: ES= eco de spins; Espess./interv.= espessura do corte/ intervalo entre os cortes; ESR= eco de spins rápido; FLAIR = fluid attenuated inversion recovery; $\mathrm{mm}=$ milímetros; $\mathrm{ms}=$ milissegundos; $\mathrm{NEX}=$ número de excitações por ciclo; $\mathrm{TE}=$ tempo de eco; $\mathrm{TI}=$ tempo de inversão; $\mathrm{TR}=$ tempo de repetição. 


\section{Análise das imagens estruturais de ressonância magnética}

Inicialmente, as IRM dos pacientes foram avaliadas quanto à presença ou não de dilatação ventricular; os demais espaços liquóricos também foram avaliados quanto a sua acentuação em detrimento do parênquima encefálico, inferindo atrofia.

As IRM do parênquima encefálico foram analisadas em relação à presença de lesão com hipersinal na sequência de difusão, nas seqüências pesadas em T2 e FLAIR.

Quanto à localização das lesões, foram avaliadas as seguintes estruturas: os núcleos da base (putâmes, globos pálidos e núcleos caudados); o diencéfalo (tálamos e região subtalâmica); o mesencéfalo (substância cinzenta periaquedutal); e a substância branca cerebral (Kaufmann, Koga et al. 1996). Foi observada, também, a concomitância de sinais de redução volumétrica dessas estruturas.

As alterações parenquimatosas, no entanto, estão além do escopo desta tese.

\section{Espectroscopia de prótons por ressonância magnética}

A ERM foi realizada pela técnica de VOI único, que consiste em uma amostragem tridimensional de uma região pré-selecionada graficamente em uma imagem convencional de RM, dita localizadora.

A seqüência utilizada como localizadora, neste estudo, foi obtida no plano axial, ESR, ponderada em T2, com os seguintes parâmetros: $\mathrm{TR}=3000 \mathrm{~ms}$; $\mathrm{TE}=88$ 
ms; espessura de corte / intervalo entre os cortes $=10,0 / 0,0 \mathrm{~mm}$; matriz $=256 \times 256$; número de excitações por ciclo $(\mathrm{NEX})=1,0$.

A técnica utilizada para obtenção da ERM foi o modo de aquisição baseado em PRESS, com o uso de TE longo (144 ms), pois favorece a caracterização do pico de lactato.

A ERM, utilizando a técnica PRESS no presente estudo, foi obtida com os seguintes parâmetros: $\mathrm{TR}=1500 \mathrm{~ms} ; \mathrm{TE}=144 \mathrm{~ms}$; tempo de mistura $(\mathrm{TM})=13,7 \mathrm{~ms}$; espessura do $\mathrm{VOI}=20,0 \mathrm{~mm}$; matriz $=512 \times 512 ; \mathrm{NEX}=8$; largura da banda de freqüência $=2500 \mathrm{~Hz}$. O número de aquisições foi de 128 .

A aquisição desta seqüência foi precedida por uma série de tarefas que consistem numa pré-aquisição automatizada, a saber: ajuste do receptor e transmissor, otimização do ângulo de inclinação para a supressão da água e ajuste da homogeneidade do campo magnético para o VOI, que foi pré-selecionado em $8 \mathrm{~cm}^{3}$ para análise do parênquima e de volume variável para os ventrículos laterais, conforme suas configurações. A largura do pico da água aceitável, após o ajuste da homogeneidade do campo, foi sempre menor que $6 \mathrm{~Hz}$.

O tempo de aquisição de cada sequência de ERM foi de aproximadamente 5 minutos. 


\section{Localização dos volumes de interesse}

Foram escolhidos quatro VOI: substância cinzenta profunda e cortical parieto-occipital, substância branca parieto-occipital e ventrículos laterais.

O VOI na substância cinzenta profunda foi posicionado preferencialmente na região dos núcleos da base e, por proximidade, também incluiu parcialmente o tálamo [Figura 1]; o VOI localizado na cortical parieto-occipital [Figura 2] abrangeu a substância cinzenta paramediana dos lobos occipitais e parietais; o VOI na substância branca occipital englobou basicamente a substância branca periventricular junto do corno posterior do ventrículo lateral [Figura 3]; o VOI nos ventrículos laterais foi posicionado de modo a compreender a maior extensão possível dessas estruturas, nas regiões dos cornos anteriores e dos corpos [Figura 4].

O tamanho dos VOI foi padronizado em $2 \times 2 \times 2 \mathrm{~cm}$ (volume de $8 \mathrm{~cm}^{3}$ ) para todos os pacientes nas três localizações parenquimatosas e foi variável nos ventrículos laterais, conforme a configuração dos mesmos, variando de 6,4 a 26,9 $\mathrm{cm}^{3}$. 


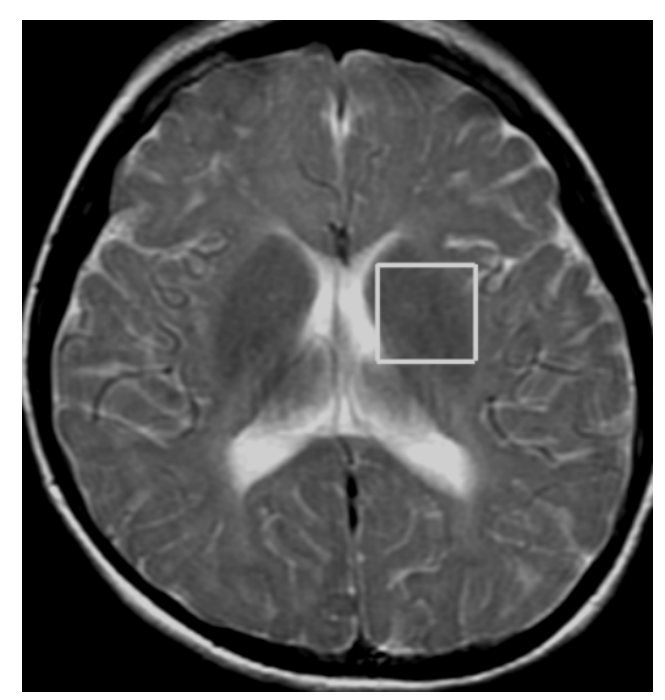

FIGURA 1- Imagem no plano axial ponderada em T2 demonstrando a localização do volume de interesse na região dos núcleos da base e tálamo

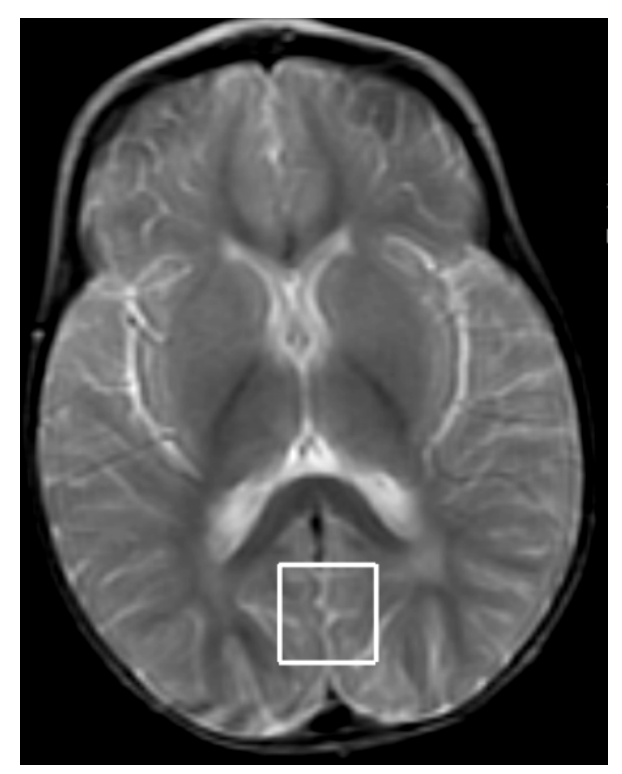

FIGURA 2- Imagem no plano axial ponderada em T2 demonstrando a localização do volume de interesse na cortical parieto-occipital 


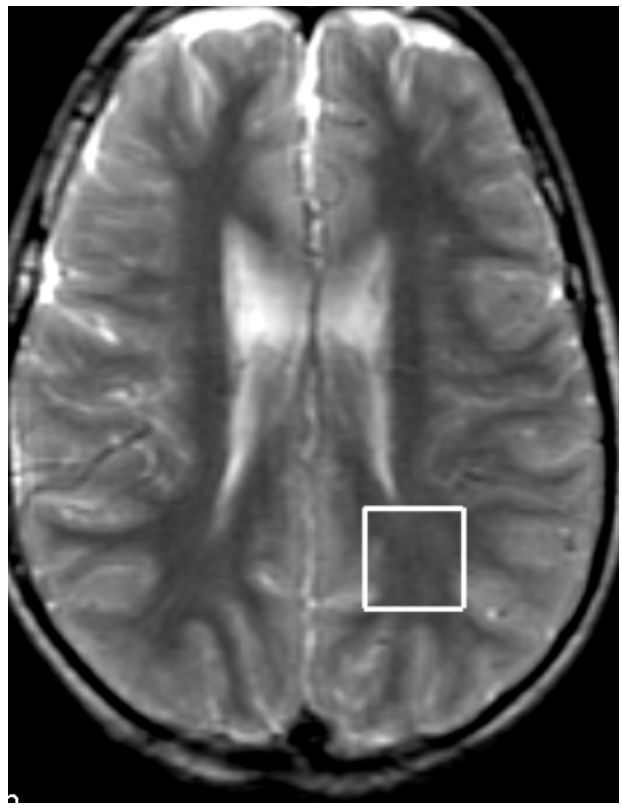

FIGURA 3- Imagem no plano axial ponderada em T2 demonstrando a localização do volume de interesse na substância branca parieto-occipital

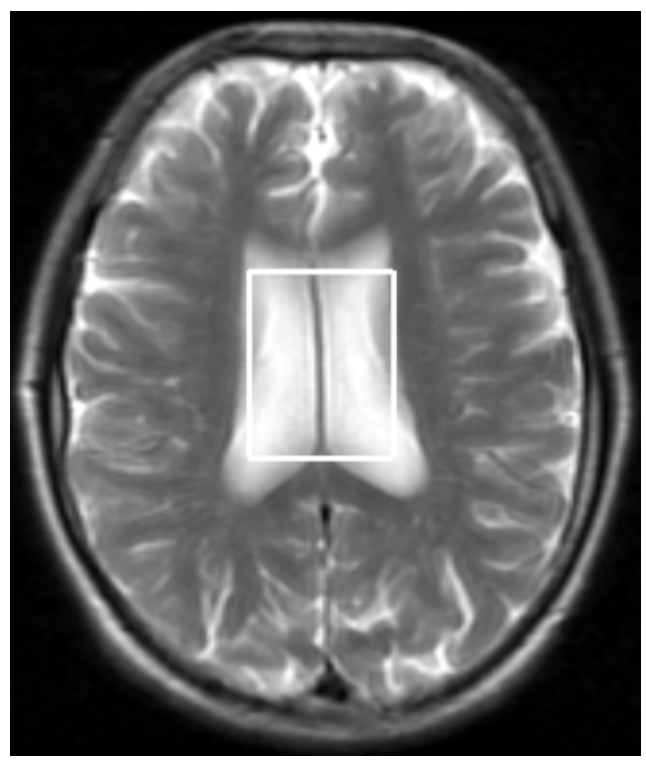

FIGURA 4- Imagem no plano axial ponderada em T2 demonstrando a localização do volume de interesse nos ventrículos laterais 


\section{Armazenamento dos dados brutos das ERMs}

Para a análise das ERMs, foi utilizado o programa LCModel (LCModel, S.W. Provencher Inc., Oakville, ON, Canada) (Provencher 1993); foi necessário, para tanto, o armazenamento dos dados brutos obtidos das espectroscopias, transferidos a partir do aparelho de RM para um servidor e, posteriormente, para um computador pessoal, utilizando-se o protocolo FTP (File transfer protocol). No computador pessoal, contendo o programa LCModel, a análise spectral foi realizada por uma espectroscopista com nove anos de experiência (M.C.G.O.).

Realizou-se o pós-processamento das espectroscopias de cada paciente que apresentou presença do pico de lactato em qualquer das localizações estudadas.

\section{Processamento dos dados brutos das ERMs}

Para o pós-processamento das espectroscopias foi, como acima descrito, utilizado o programa LCModel, que é um software que permite análises espectroscópicas no domínio da freqüência. Esse programa analisa o espectro in vivo como uma combinação linear de uma base espectral completa de solução de metabólitos in vitro (Kanowski, Kaufmann et al. 2004). Utilizando-se o espectro completo em vez de picos individuais, todas as informações deste espectro são processadas (Provencher 1993). Outra vantagem do LCModel é que ele estima automaticamente a concentração absoluta dos metabólitos, utilizando como referência a água contida no volume de interesse escolhido para o estudo. Desta 
maneira, cada metabólito pode ser estudado independentemente. O maior problema da quantificação in vivo do espectro é estabelecer modelos-padrão para a linha de base e para a distorção dos picos, que são bastante complicados para serem estabelecidos previamente. Modelos empíricos com poucos parâmetros produzem viés nos resultados. Parâmetros em demasia provocam artefatos e erros nas análises. O LCModel utiliza um modelo que escolhe a melhor combinação entre estas duas situações, procurando uma linha de base mais consistente com os dados obtidos (Provencher 1993).

\section{Análise estatística}

Inicialmente, todas as variáveis foram analisadas de forma descritiva. Para as variáveis quantitativas - relações entre os valores aferidos do lactato à ERM, no LCR e no sangue (itens 5.1 e 5.3) - a análise foi feita de maneira pareada através do coeficiente de Pearson, também denominado de coeficiente de correlação momentoproduto; essa é uma medida que avalia a correlação entre duas variáveis, ou seja, averigua a existência de correlação linear. Assim, é possível medir a força de dependência linear entre essas duas variáveis, valor esse que se situa entre -1 e +1 .

O valore de $\mathrm{p}$ considerado significativo foi de 0,5 . 
5 - Resultados 


\section{1 - Valores do lactato nas dosagens séricas e liquóricas e avaliação de existência de correlação entre os mesmos}

Dez pacientes apresentaram lactato elevado na dosagem bioquímica do LCR e quatro, na dosagem sérica dessa mesma substância (tabela 2); o aumento concomitante do lactato no LCR e no sangue foi observado em dois pacientes. 
TABELA 2 - Lista dos pacientes, relação da identificação $(+)$ ou não identificação (-) do PL à ERM, nas diferentes localizações estudadas, e resultados das dosagens bioquímicas do lactato liquórico e sanguíneo

\begin{tabular}{|c|c|c|c|c|c|c|}
\hline Paciente & $\begin{array}{c}\text { PL } \\
\text { VVLL }\end{array}$ & $\begin{array}{l}\mathrm{PL} \\
\mathrm{NB}\end{array}$ & $\begin{array}{c}\text { PL } \\
\text { SBPO }\end{array}$ & $\begin{array}{c}\text { PL } \\
\text { SCPO }\end{array}$ & $\begin{array}{c}\text { Lactato sérico } \\
\mathrm{mg} / \mathrm{dL}\end{array}$ & $\begin{array}{c}\text { Lactato liquórico } \\
\mathrm{mg} / \mathrm{dL}\end{array}$ \\
\hline 1 & - & - & - & - & 9,1 & 22,1 \\
\hline 2 & + & - & - & - & 8 & 12,3 \\
\hline 3 & - & - & - & - & 6,4 & 11,2 \\
\hline 4 & - & - & - & - & 10,9 & 13 \\
\hline 5 & + & - & + & - & 14,8 & 34,9 \\
\hline 6 & + & - & - & - & 75 & 9,1 \\
\hline 7 & + & - & - & - & 8 & 14 \\
\hline 8 & + & - & - & - & 53 & 35,4 \\
\hline 9 & + & - & - & - & 8 & 15,7 \\
\hline 10 & + & - & - & - & 12,5 & 34,4 \\
\hline 11 & + & - & - & - & 13 & 15,1 \\
\hline 12 & + & + & - & - & 12,5 & 30,3 \\
\hline 13 & + & - & - & - & 34,1 & 8,5 \\
\hline 14 & + & - & - & - & 12,9 & 15,2 \\
\hline 15 & - & - & - & - & 15,1 & 13,3 \\
\hline 16 & + & - & - & - & 9 & 16,3 \\
\hline 17 & + & + & - & - & 20,3 & 35,2 \\
\hline 18 & + & - & - & - & 11,3 & 17,3 \\
\hline 19 & + & + & - & - & 12 & 34,0 \\
\hline 20 & + & + & - & - & 14,4 & 16,5 \\
\hline 21 & + & - & - & - & 18,9 & 15,3 \\
\hline
\end{tabular}

Nota: $\mathrm{PL}=$ pico do lactato; $\mathrm{VVLL}=$ ventrículos laterais; $\mathrm{NB}=$ núcleos da base; $\mathrm{SBPO}=$ substância branca parieto-occipital; $\mathrm{SCPO}=$ substância cinzenta parieto-occipital. 
O gráfico 2 demonstra a dispersão entre os valores obtidos de lactato liquórico e sanguíneo.

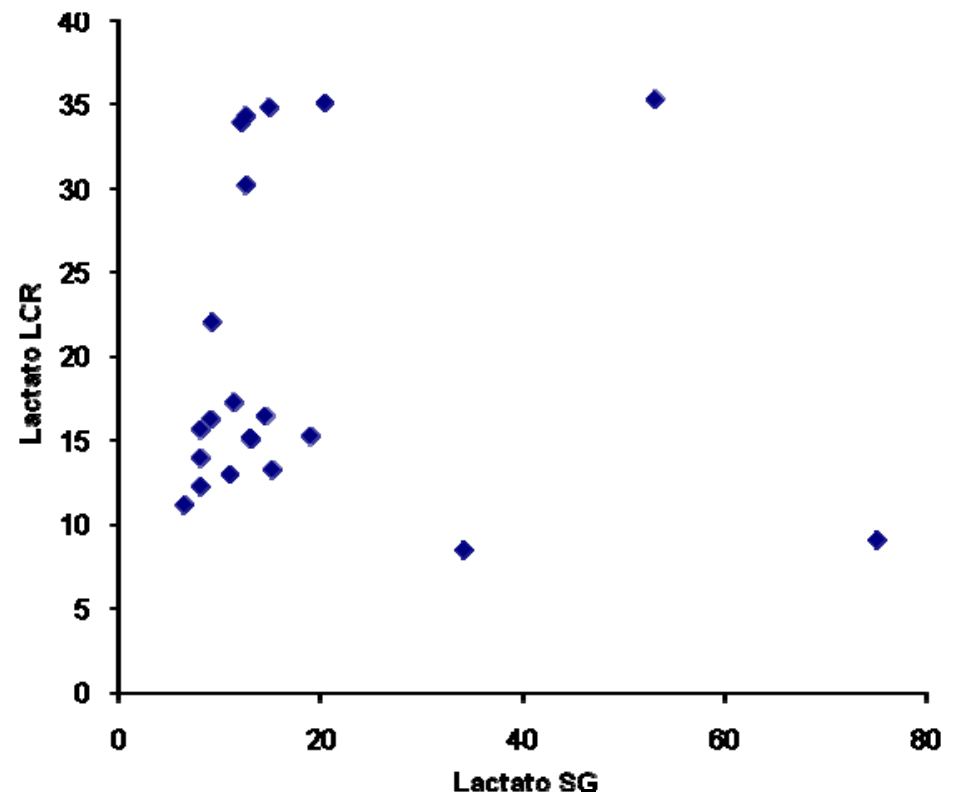

GRÁFICO 2 - Gráfico de dispersão entre os valores obtidos de lactato liquórico (LCR) e sanguíneo (SG) 
A análise de correlação não demonstrou evidências de associação entre essas duas variáveis $(\mathrm{p}=0,937)($ tabela 3$)$.

TABELA 3 - Análise de Correlação Linear de Pearson das variáveis PL à ERM, lactato no LCR e lactato sérico pareadas duas a duas, valores dos coeficientes de $\mathrm{p}$

\begin{tabular}{lcc}
\hline \multicolumn{3}{c}{ Análise de Correlação Linear de Pearson } \\
\hline coeficiente & p-valor \\
\hline PL à ERM x lactato LCR & 0,742 & $\mathbf{0 , 0 0 1}$ \\
PL à ERM x lactato sérico & 0,088 & 0,736 \\
lactato LCR x lactato sérico & $-0,018$ & 0,937 \\
\hline
\end{tabular}

Nota: $\mathrm{PL}=$ pico do lactato; $\mathrm{ERM}=$ espectroscopia de próton por ressonância magnética; $\mathrm{LCR}=$ líquor. 


\section{2 - Presença do pico do lactato na espectroscopia de prótons}

Dezessete pacientes apresentaram PL nos VVLL [Figura 5], tendo sido esse mesmo pico detectado em um paciente na SBPO [Figura 6] e em outros quatro pacientes nos NB [Figura 7] (tabela 2).

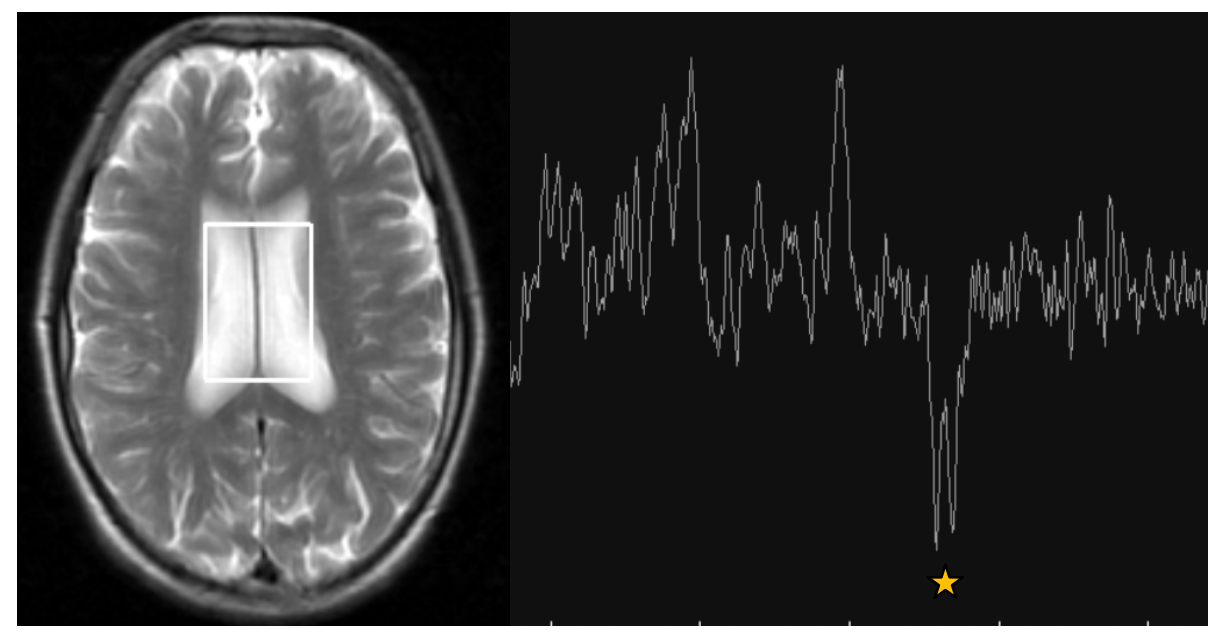

FIGURA 5 - Imagem no plano axial ponderada em T2 demonstrando a localização do VOI nos ventrículos laterais e o espectro correspondente evidenciando PL (它) do paciente 9

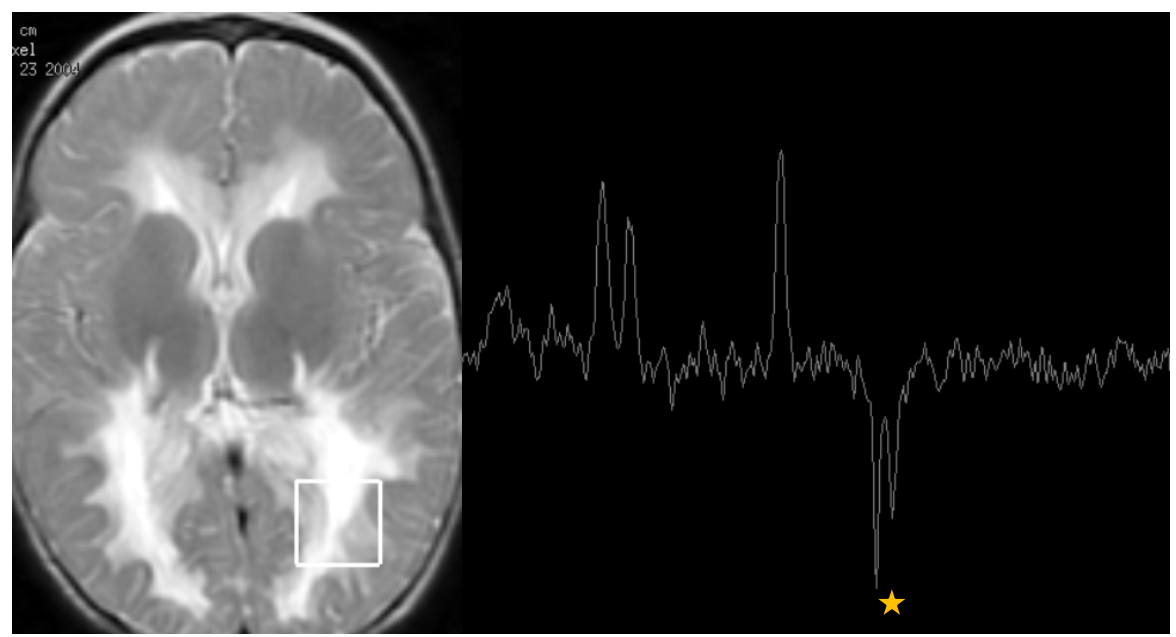

FIGURA 6 - Imagem no plano axial ponderada em T2 demonstrando a localização do VOI na SBPO e o espectro correspondente evidenciando PL (㝋) do paciente 6 


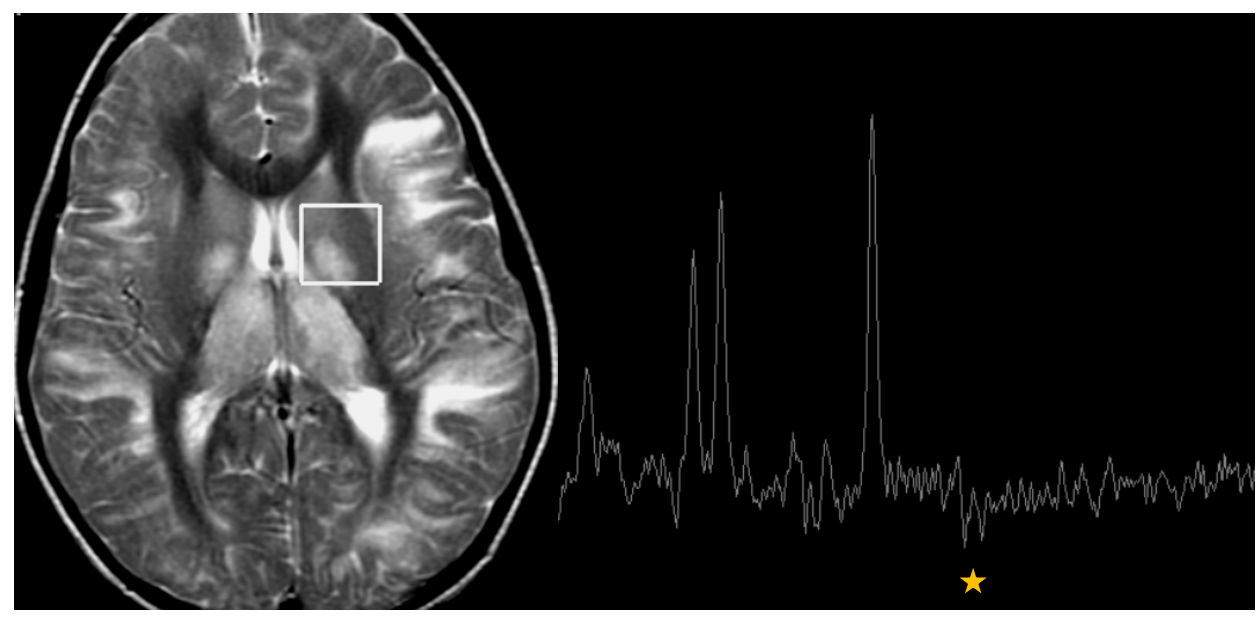

FIGURA 7 - Imagem no plano axial ponderada em T2 demonstrando a localização

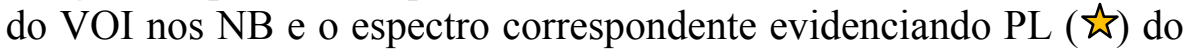
paciente 6

Todos os cinco pacientes, nos quais o PL foi identificado no parênquima, apresentram o PL nos VVLL (tabela 2). 


\section{3 - Verificação da existência de correlação entre a presença do pico do lactato na espectroscopia de prótons dos pacientes nos ventrículos laterais com as dosagens séricas e liquóricas do mesmo}

O PL foi caracterizado em dezessete pacientes, incluindo oito em que a dosagem bioquímica do LCR estava elevada; assim, nove pacientes apresentaram à ERM a presença do PL com valores liquóricos normais à dosagem bioquímica (tabela 2).

Em quatro pacientes que não apresentaram PL à ERM, dois exibiram valores liquóricos aumentados do lactato (tabela 2).

Os volumes de cada VOI nos VVLL, os valores do PL à RM, o erro percentual e resultados das dosagens bioquímicas do lactato liquórico e sanguíneo foram descritos na tabela 4. 
TABELA 4 - Relação de pacientes, volumes do VOI nos VVLL, valores do PL à RM calculado pelo LCmodel, erro percentual do cálculo do valor do PL através do LCmodel e resultados das dosagens bioquímicas do lactato liquórico e sanguíneo

\begin{tabular}{|c|c|c|c|c|c|}
\hline Paciente & $\begin{array}{l}\text { Volume do VOI } \\
\text { nos VVLL } \\
(\mathrm{mL})\end{array}$ & $\begin{array}{l}\text { Valor do } \\
\text { PL à RM }\end{array}$ & $\begin{array}{c}\text { Erro } \\
\text { percentual }\end{array}$ & $\begin{array}{l}\text { Lactato } \\
\text { sérico } \\
\mathrm{mg} / \mathrm{dL}\end{array}$ & $\begin{array}{l}\text { Lactato } \\
\text { liquórico } \\
\mathrm{mg} / \mathrm{dL}\end{array}$ \\
\hline 1 & 15,4 & - & - & 9,1 & 22,1 \\
\hline 2 & 26,9 & 1,88 & 0,17 & 8 & 12,3 \\
\hline 3 & 13,8 & - & - & 6,4 & 11,2 \\
\hline 4 & 10,5 & - & - & 10,9 & 13 \\
\hline 5 & 10,3 & 6,414 & 0,13 & 14,8 & 34,9 \\
\hline 6 & 12,3 & 1,304 & 0,42 & 75 & 9,1 \\
\hline 7 & 12,9 & 1,212 & 0,22 & 8 & 14 \\
\hline 8 & 16,2 & 4,003 & 0,24 & 53 & 35,4 \\
\hline 9 & 6,4 & 3,029 & 0,33 & 8 & 15,7 \\
\hline 10 & 9,4 & 3,240 & 0,2 & 12,5 & 34,4 \\
\hline 11 & 9,8 & 2,389 & 0,32 & 13 & 15,1 \\
\hline 12 & 8,4 & 8,115 & 0,13 & 12,5 & 30,3 \\
\hline 13 & 9 & 1,988 & 0,23 & 34,1 & 8,5 \\
\hline 14 & 10,5 & 1,991 & 0,25 & 12,9 & 15,2 \\
\hline 15 & 7,2 & - & - & 15,1 & 13,3 \\
\hline 16 & 9,5 & 1,519 & 0,2 & 9 & 16,3 \\
\hline 17 & 12,1 & 4,701 & 0,16 & 20,3 & 35,2 \\
\hline 18 & 8 & 1,398 & 0,39 & 11,3 & 17,3 \\
\hline 19 & 13,7 & 3,390 & 0,13 & 12 & 34,0 \\
\hline 20 & 14 & 1,664 & 0,23 & 14,4 & 16,5 \\
\hline 21 & 9,8 & 1,488 & 0,21 & 18,9 & 15,3 \\
\hline
\end{tabular}

Nota: $\mathrm{PL}=$ pico do lactato; $\mathrm{VVLL}=$ ventrículos laterais. 
Os gráficos 3 e 4 demonstram a dispersão entre todos os valores obtidos de lactato à ERM em relação aos valores liquórico e sangüíneo, respectivamente. Os gráficos 5 e 6 demonstram a dispersão entre os valores obtidos de lactato à ERM com erro inferior a 30\% em relação às mesmas variáveis analisadas anteriormente (valores liquórico e sangüíneo).

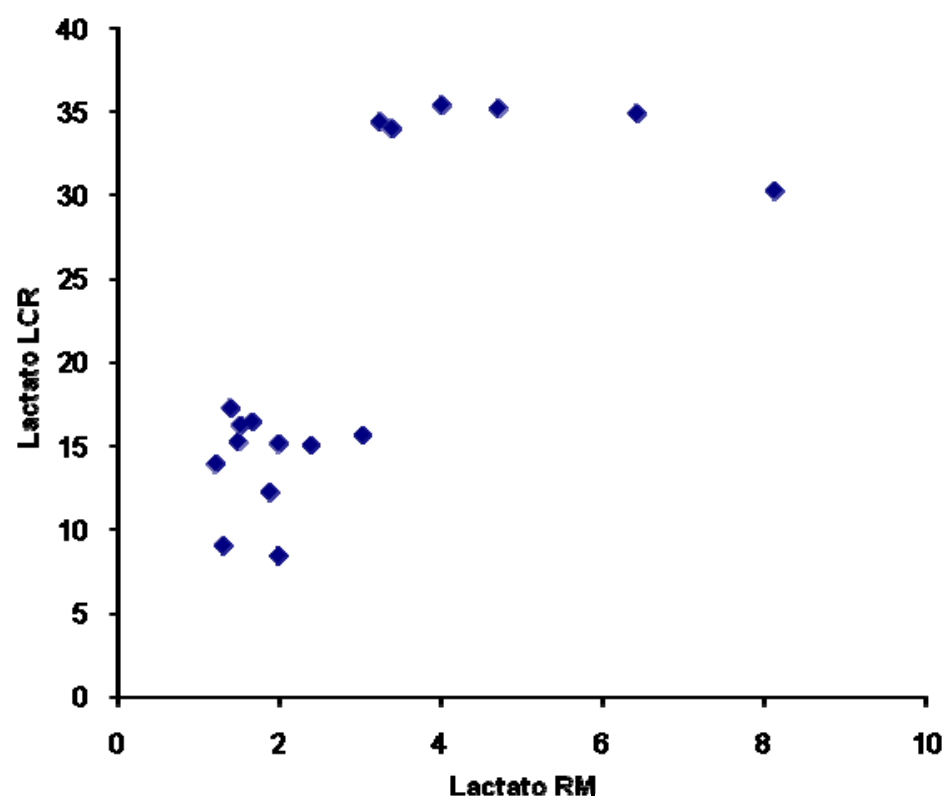

GRÁFICO 3 - Gráfico de dispersão entre os valores obtidos de lactato à ERM (RM) e o liquórico (LCR) 


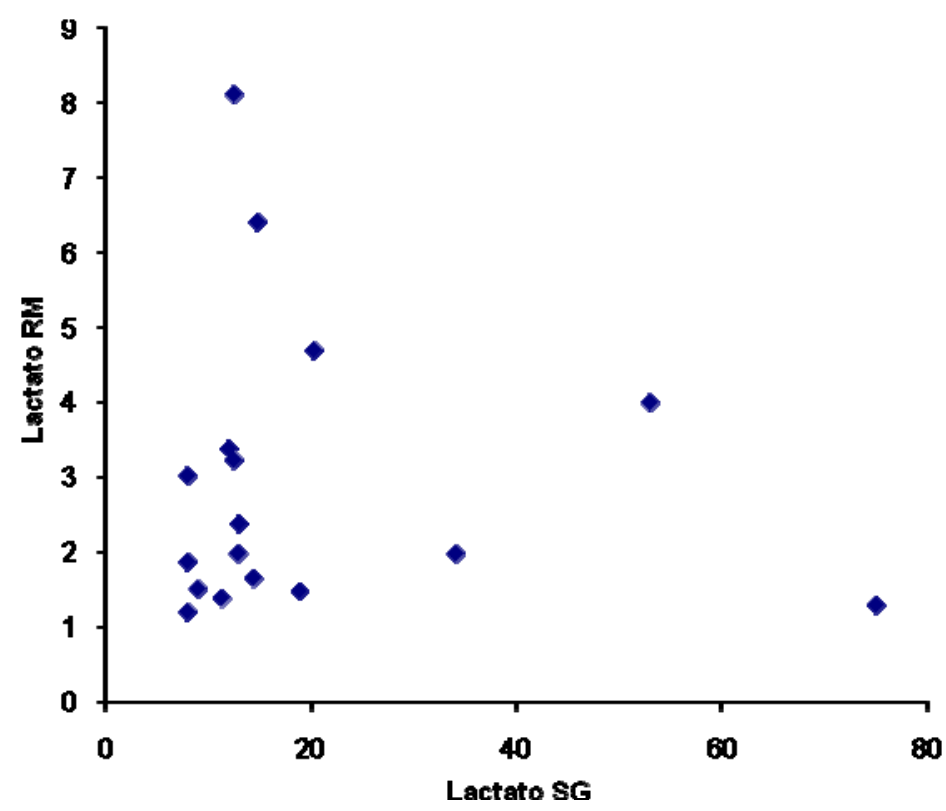

GRÁFICO 4 - Gráfico de dispersão entre os valores obtidos de lactato à ERM (RM) e o sanguíneo (LCR)

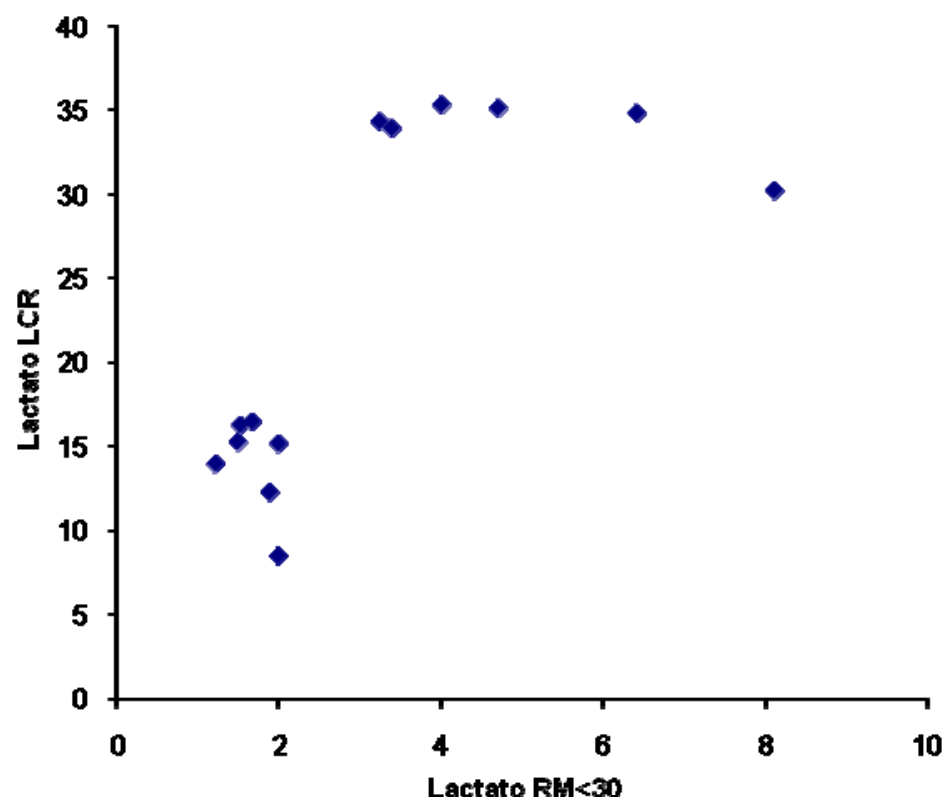

GRÁFICO 5 - Gráfico de dispersão entre os valores obtidos de lactato à ERM (RM) e o liquórico (LCR) considerando os valores com erro inferiores a $30 \%$ 


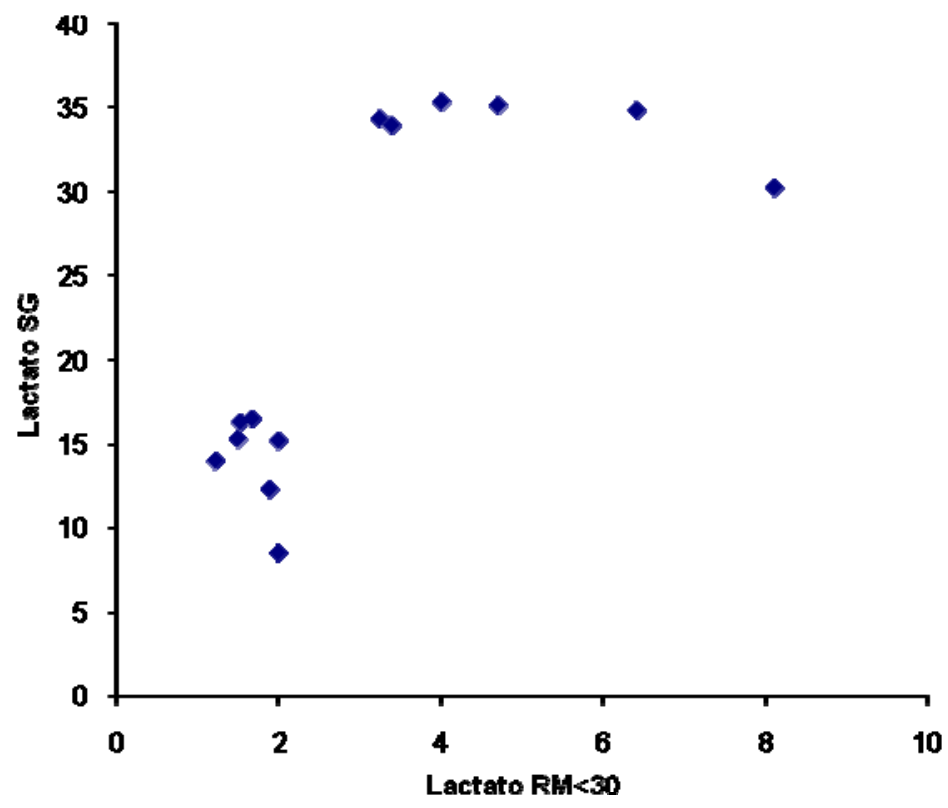

GRÁFICO 6 - Gráfico de dispersão entre os valores obtidos de lactato à ERM (RM) e o sanguíneo (LCR) considerando os valores com erro inferiores a $30 \%$

A análise de correlação demonstrou evidências de associação entre as variáveis lactato à ERM e lactato liquórico, considerando todos os valores ou mesmo quando apenas os valores obtidos à RM eram aqueles com erro inferior a 30\% (p = 0,001 e p $=0,005$, respectivamente) (tabela 3 ).

A análise de correlação não demonstrou evidências de associação entre os valores de lactato à ERM e as medidas sanguíneas dessa substância $(p=0,736)$ ou entre as medidas bioquímicas realizadas no liquor e no sangue $(p=0,937)$. 
6 - Discussão 
A RM é uma ferramenta fundamental para avaliação das DM, tanto para o diagnóstico quanto para o acompanhamento dessas enfermidades (Mathews, Andermann et al., 1993; Pavlakis, Kingsley et al., 1998; Lin, Crawford et al., 2003). Constitui um método de imagem que permite avaliar os aspectos estruturais do encéfalo bem como alterações metabólitas in vivo, sendo estas últimas avaliadas tanto no parênquima encefálico quanto no LCR.

O lactato é um dos metabólitos que pode ser caracterizado pela ERM; seu aumento no encéfalo está relacionado à disfunção da respiração celular, o que pode ser determindo por diversos fatores causais, como, por exemplo, hipoxemia ou anoxemia, neoplasias, infecções bacterianas, insuficiência cardíaca, insuficiência hepática e estado epiléptico, citando apenas alguns. Nesse aspecto, o aumento dessa substância é um achado inespecífico; entretanto, dentro do contexto clínico adequado, na investigação diagnóstica de pacientes com suspeita de DM, sua detecção pela ERM é um achado importante (Benoist, Alberti et al., 2003; Zschocke e Hoffmann, 2004). No seguimento do paciente com DM, a ERM com caracterização do PL no parênquima também aparenta ser um instrumento útil na monitorização da evolução clínica, pois alterações metabólicas podem preceder as estruturais (Pavlakis, Kingsley et al., 1998).

A concentração de lactato no LCR está relacionada ao balanço entre o influxo e o efluxo dessa substância através da barreira hematoencefálica e da membrana citoplasmática das células do SNC (Benoist, Alberti et al., 2003). O equilíbrio entre as concentrações plasmática e liquórica ocorre lentamente em função da taxa baixa de permeação dessa substância, do encéfalo para a corrente sanguínea, e em função 
da extração lenta que ocorre a partir do sangue (LaManna, Harrington et al., 1993). Assim, assume-se que variações do lactato no LCR, em curtos períodos de tempo, podem ocorrer independentemente de alterações de sua concentração sanguínea (Posner e Plum, 1967; Kuriyama, Umezaki et al., 1984; Jackson, Schaefer et al., 1995; Stacpoole, Bunch et al., 1999); por isso, a dosagem do lactato no LCR é considerado um marcador mais adequado, quando comparado à amostragem sanguínea, em quadros agudos de desordens do metabolismo aeróbico (Benoist, Alberti et al., 2003). Sua distribuição tende a ser homogênea no LCR, sendo, assim, representativa do conteúdo intraventricular, a amostra lombar (Gerber, Tumani et al., 1998; Sommer, Gaul et al., 2002).

Em nossa casuística, foi observado, através da dosagem bioquímica, o aumento do lactato sérico e do liquórico em quatro e dez pacientes, respectivamente; o aumento concomitante foi caracterizado em dois pacientes.

O aumento isolado do lactato sérico, observado em dois pacientes, pode ser primário ou secundário. A acidemia láctica crônica está relacionada a erros inatos do metabolismo que comprometem a gliconeogênese, a oxidação do piruvato, o ciclo de Krebs e a cadeia respiratória (Burton, 1998). A causa mais comum de acidemia secundária é o uso de garroteamento para punção de uma veia; desse modo, é recomendado que a mesma seja realizada sem garroteamento, com a criança relaxada, ou que seja feita a punção de uma artéria. A atividade muscular, decorrente da agitação do paciente, e a apnéia ou irregularidade da respiração, consequentes do choro, também são fatores que podem resultar no aumento sérico e pontual dessa substância; além disso, existem variações relacionadas após período de jejum e após as refeições (Zschocke e Hoffmann, 2004). A insuficiência cardíaca ou hepática, a 
septicemia, a diabetes melitus, a infecção do trato urinário, a síndrome tubular renal, o uso de fármacos (biguanidas) e a intoxicação por etanol constituem outras causas secundárias de acidemia láctica. Outra possibilidade é o comprometimento preferencial de sistemas que não do $\mathrm{SNC}$, como, por exemplo, músculo-esquelético (Zschocke e Hoffmann, 2004). No presente estudo, as amostras saguíneas dos primeiros pacientes foram obtidas logo após a punção de veia periférica realizada para a sedação, o que aumentou a susceptibilidade ao erro por falta de cooperação dos pacientes, como descrito antes; posteriormente, a coleta foi realizada com o paciente sedado, o que excluiu a possibilidade de resultado falso positivo por agitação psicomotora. Os pacientes que não necessitaram de sedação (pacientes 1, 9 e 19) cooperaram adequadamente para a coleta do material e os valores de suas dosagens de lactato sérico estavam dentro dos limites da normalidade.

$\mathrm{O}$ aumento isolado do lactato liquórico pode ser decorrente do momento em que foi obtida a amostra, pois, como citado anteriormente, variações do lactato no LCR, em curtos períodos de tempo, podem ocorrer independentemente de alterações de sua concentração sanguínea (Posner e Plum, 1967). Ademais, essa substância apresenta uma extração lenta do LCR para o sangue (LaManna, Harrington et al., 1993) e, então, a mensuração sanguínea, cujo valor é normal, pode refletir um momento anterior à sua elevação. Inao e cols. em seu experimento, utilizando um modelo de traumatismo encefálico em gatos, descreveram um padrão de elevação bifásico do lactato liquórico. A primeira elevação do lactato estaria relacionada ao evento por si só e o segundo, ao clearance do lactato do parênquima para o LCR; assim, a janela temporal de detecção do lactato deve ser mais longa no LCR do que no tecido encefálico (Inao, Marmarou et al., 1988). Desta forma, a elevação 
exclusiva do lactato no LCR, também pode ser decorrente do segundo pico de elevação do lactato.

A simultaneidade do aumento do lactato no sangue e no LCR pode ser decorrente do momento em que o estudo foi realizado, quando tenhamos mensurado essa substância num período pós-disfunção da respiração celular, mas com tempo hábil para eliminação da mesma para a corrente sanguínea; mas também pode ser decorrente de uma coleta de sangue inadequada, como já referido anteriormente.

Quanto à presença do PL à ERM, observamos que dezessete pacientes apresentaram PL nos VVLL sendo esse mesmo pico detectado em um paciente na SBPO e em outros quatro pacientes nos NB.

Todos os cinco pacientes, nos quais o PL foi identificado no parênquima, apresentaram o PL nos VVLL, fato que pode estar relacionado ao momento em que o estudo foi feito, ou seja, ou os pacientes estavam sofrendo uma descompensação, ou, mais provavelmente, já haviam passado por ela há algum tempo o qual não foi tão longo a ponto de só encontrarmos lactato no LCR.

Em relação à correlação entre a presença do pico do lactato nos ventrículos laterais na ERM e as dosagens bioquímicas do mesmo no LCR, notamos que, em nossa casuística, o PL foi identificado em dezessete dos vinte e um pacientes com suspeita de encefalopatia mitocondrial; desses, oito cursavam com aumento do lactato na dosagem bioquímica do LCR. A detecção do PL em pacientes com aumento na dosagem bioquímica dessa substância no LCR já foi descrita anteriormente na literatura médica, porém, em uma série pequena, com estudo in vitro e caso isolado (Feng, You et al., 2006; Isobe, Matsumura et al., 2007). Feng e 
cols. relataram uma série de sete pacientes diagnosticados com MELAS com ERM do LCR diponível em três pacientes e dosagem liquórica do lactato para dois destes; nesses três pacientes houve a identificação do PL e a dosagem bioquímica da substância estava aumentada nas duas amostras obtidas. (Feng, You et al., 2006). Deste modo, os autores sugerem que a ERM do LCR apresenta potencial para substituir a dosagem bioquímica do lactato e assim evitar um procedimento invasivo (Feng, You et al., 2006). Isobe e cols. utilizaram seis phantoms com concentrações variadas de lactato (1 a 14 mmol/L) e realizaram uma avaliação em um paciente com MELAS; através do cálculo do tempo de relaxação T2 do lactato, obtiveram uma correlação com coefíciente de 0,99 em relação à dosagem bioquímica prédeterminada (Isobe, Matsumura et al., 2007).

Assim, foi observado que mesmo em concentrações liquóricas consideradas normais, o lactato pode apresentar expressão à ERM. Esse achado corrobora os dados de Braun e cols. (Braun, Gooskens et al., 2003) que demonstraram que o PL pode ser caracterizado à ERM mesmo em pacientes com valores normais de lactato no LCR, e contradiz trabalhos anteriores em que essa substância não era detectada pela ERM, tanto em estudos com voluntários sãos bem como em análises comparativas com grupos controles (Cross, Gadian et al., 1993; Duyn, Gillen et al., 1993; Soher, Hurd et al., 1996; Braun, Gooskens et al., 2003; Lin, Crawford et al., 2003). Diferentemente de Cross e cols. que demonstraram um PL consistente apenas para pacientes com valores de lactato no LCR acima de 4,0 mmol/L, tendo os mesmos sugerido que, na faixa compreendida entre 3,2 a 4,0 $\mathrm{mmol} / \mathrm{L}$, embora sejam valores considerados alterados, a identificação do pico de lactato pode estar abaixo do limite de resolução do método (Cross, Gadian et al., 1993) e Lin et cols. que referem que o 
método teria sensibilidade para uma concentração superior a $1 \mathrm{mmol} / \mathrm{L}$ do metabólito (Lin, Crawford et al., 2003), foi observada a caraterização do PL com valores normais, sendo que o paciente 13 apresentava concentração de $0,9435 \mathrm{mmol} / \mathrm{L}$. As limitações do artigo de Braun e cols são o número restrito de amostras de LCR, disponível em oito de seus vinte e quatro pacientes, e o tempo de intervalo de coleta do material que variou de um dia a quatro semanas após o exame de RM (Braun, Gooskens et al., 2003).

Em nossa série, o PL foi caracterizado em nove pacientes com valores normais dessa substância no LCR. Em geral, o sinal do lactato no LCR é maior do que o caracterizado no parênquima (Castillo, Kwock et al., 1995). Uma possibilidade seria que essa substância se encontra em uma concentração maior no LCR, quando comparada ao parênquima; outra hipótese, considerando as propriedades relacionadas à $\mathrm{RM}$, implica a característica de um tempo de relaxação T2 longo e as bandas lineares estreitas do LCR, quando comparadas ao parênquima (Braun, Gooskens et al., 2003; Lin, Crawford et al., 2003; Nagae-Poetscher, McMahon et al., 2004). Outro aspecto considerado por Braun e cols. foi a utilização de um VOI com grande volume de LCR, como em sua série em que o volume médio foi de 33,5 mL, com valores entre 8 a 96 mL, o que elevaria a relação sinal-ruído (Braun, Gooskens et al., 2003). Entretanto, em nossa série de pacientes, o volume do menor VOI em que foi observado o PL foi $6,4 \mathrm{~mL}$, contrariando esta hipótese.

O PL não foi evidenciado em quatro pacientes (1, 3, 4 e 15), sendo que um deles (paciente 1) apresentou aumento do lactato no LCR $(22,1 \mathrm{mg} / \mathrm{dL})$. O paciente 1 realizou a ERM nos VVLL duas vezes, porque a qualidade do primeiro espectro era inadequada, por este ser muito ruidoso, e, portanto, inadequado para a análise; assim, 
foi utilizado o segundo espectro. $\mathrm{O}$ volume nas duas aquisições foi de $15,4 \mathrm{~mL}$. A não caracterização do PL nesses pacientes pode estar relacionada à variabilidade das medidas dos metabólitos, conforme demonstrado por vários autores (Marshall, Wardlaw et al., 1996; Brooks, Friedman et al., 1999; Li, Babb et al., 2002). Coeficientes de variação entre 0,9 e $40 \%$ foram observados por estes autores e os fatores relacionados são movimentação do paciente, presença de artefatos na linha de base do espectro e variação na relação sinal-ruído.

Contrariando o afirmado anteriormente por Rocha e cols., ou seja, que uma boa correlação entre a ERM do LCR com o lactato liquórico só é observada quando o PL está anormalmente elevado à ERM e que uma pequena quantidade de lactato pode não ser detectada pela ERM isoladamente (Jose da Rocha, Tulio Braga et al., 2008), em nossa casuística, o valor mínimo do lactato no LCR com detecção do PL foi $8,5 \mathrm{mg} / \mathrm{dL}$ (paciente 13 ).

Em resumo, pelos resultados obtidos em nossa série, observamos que a ERM do LCR é uma técnica factível e recomendamos que a mesma seja empregada rotineiramente em pacientes com suspeita ou em seguimento de EM; que, mesmo frente a dosagens bioquímicas do lactato no LCR, demonstrando valores normais e mais baixos que os citados em artigos anteriores, o PL pode ser identificado; que os valores dos VOIs citados na literatura como relativamente pequenos, não constituem impedimento ao emprego desse método. 
7 - Conclusões

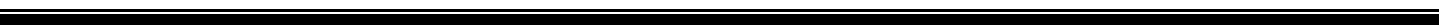


1- Não foi observada a existência de correlação entre os valores do lactato nas dosagens séricas e liquóricas;

2- A comparação da presença do pico do lactato na espectroscopia de protons dos pacientes em quatro localizações (ventrículos laterais, núcleos da base, substância branca e córtex parietoccipital) evidenciou:

- que a detecção do PL no LCR foi possível em maior número de pacientes do que a detecção do PL no parênquima cerebral.

3- A verificação de correlação entre a presença do pico do lactato nos ventrículos laterais na espectroscopia de prótons dos pacientes com DM e as dosagens séricas e liquóricas do mesmo evidenciou:

- a existência de correlação entre a presença do pico do lactato nos ventrículos laterais à ERM e a dosagem bioquímica dessa substância no LCR;

- a inexistência de correlação entre a presença do pico do lactato nos ventrículos laterais à ERM e a dosagem bioquímica dessa substância no sangue. 
Anexos

ביר 
ANEXO 1 - Relação dos pacientes, registro geral no Hospital das Clínicas, data da realização do exame, gênero e idade.

\begin{tabular}{|c|c|c|c|c|}
\hline Paciente & Gênero & data do exame & $\begin{array}{c}\text { Idade } \\
\text { (anos e meses) }\end{array}$ & $\begin{array}{l}\text { Idade } \\
\text { (anos) }\end{array}$ \\
\hline 1 & Feminino & $11 / 11 / 2005$ & $8 \mathrm{a} 7 \mathrm{~m}$ & 1,58 \\
\hline 2 & Masculino & $11 / 11 / 2005$ & $11 \mathrm{~m}$ & 0,91 \\
\hline 3 & Feminino & 06/01/2006 & $7 \mathrm{a} 8 \mathrm{~m}$ & 7,66 \\
\hline 4 & Masculino & $27 / 01 / 2006$ & $3 a 2 m$ & 3,16 \\
\hline 5 & Feminino & $20 / 01 / 2006$ & $1 \mathrm{a} 4 \mathrm{~m}$ & 1,33 \\
\hline 6 & Feminino & $09 / 02 / 2006$ & $9 \mathrm{a} 2 \mathrm{~m}$ & 9,16 \\
\hline 7 & Feminino & 07/04/2006 & $3 \mathrm{a} 4 \mathrm{~m}$ & 3,33 \\
\hline 8 & Masculino & $28 / 04 / 2006$ & $18 \mathrm{a} 8 \mathrm{~m}$ & 18,66 \\
\hline 9 & Feminino & $26 / 05 / 2006$ & $8 \mathrm{a} 2 \mathrm{~m}$ & 8,16 \\
\hline 10 & Feminino & 04/08/2006 & $1 \mathrm{a} 6 \mathrm{~m}$ & 1,5 \\
\hline 11 & Feminino & $04 / 08 / 2006$ & $9 \mathrm{~m}$ & 0,75 \\
\hline 12 & Masculino & $02 / 06 / 2006$ & $9 \mathrm{a} 9 \mathrm{~m}$ & 9,75 \\
\hline 13 & Feminino & $05 / 05 / 2006$ & $1 \mathrm{a} 11 \mathrm{~m}$ & 1,91 \\
\hline 14 & Feminino & $15 / 09 / 2006$ & $4 \mathrm{a} 9 \mathrm{~m}$ & 4,75 \\
\hline 15 & Feminino & 01/09/2006 & $3 \mathrm{a} 10 \mathrm{~m}$ & 3,83 \\
\hline 16 & Masculino & 09/06/2006 & $4 \mathrm{a} 10 \mathrm{~m}$ & 4,83 \\
\hline 17 & Masculino & $20 / 10 / 2006$ & $8 \mathrm{a} 2 \mathrm{~m}$ & 8,16 \\
\hline 18 & Feminino & $06 / 10 / 2006$ & $12 \mathrm{a} 6 \mathrm{~m}$ & 12,5 \\
\hline 19 & Feminino & $30 / 11 / 2006$ & $16 \mathrm{a} 2 \mathrm{~m}$ & 16,16 \\
\hline 20 & Masculino & $18 / 08 / 2006$ & $1 \mathrm{a} 6 \mathrm{~m}$ & 1,5 \\
\hline 21 & Masculino & $27 / 10 / 2006$ & $1 \mathrm{a} 7 \mathrm{~m}$ & 1,58 \\
\hline
\end{tabular}


ANEXO 2 - TERMO DE CONSENTIMENTO PÓS-INFORMADO

Anexo I

\section{TERMO DE CONSENTIMENTO LIVRE E ESCLARECIDO}

(Instruções para preenchimento no verso)

\section{I - DADOS DE IDENTIFICAÇÃO DO SUJEITO DA PESQUISA OU RESPONSÁVEL LEGAL}

1. NOME DO PACIENTE

DOCUMENTO DE IDENTIDADE No : SEXO : $M \square F \square$ DATA NASCIMENTO:

ENDEREÇO $\mathrm{N}^{\mathrm{O}}$ APTO:

BAIRRO: CIDADE

CEP: TELEFONE:DDD ).

2.RESPONSÁVEL LEGAL

NATUREZA (grau de parentesco, tutor, curador etc.)

DOCUMENTO DE IDENTIDADE : SEXO: $M \square F \square$

DATA NASCIMENTO.: .......................

ENDEREÇO:

$\mathrm{N}^{\circ}$ APTO:

BAIRRO CIDADE:

CEP: TELEFONE: DDD (

II - DADOS SOBRE A PESQUISA CIENTÍFICA

1. TÍTULO DO PROTOCOLO DE PESQUISA ANÁLISE COMPARATIVA DA DETECÇÃO DE LACTATO NO SANGUE, NO LÍQUIDO CEFALORRAQUIDIANO E NO PARÊNQUIMA CEREBRAL AVALIADA ATRAVÉS DA ESPECTROSCOPIA DE PRÓTONS POR RESSONÂNCIA MAGNÉTICA EM PACIENTES COM ENCEFALOPATIA MITOCONDRIAL.

2. PESQUISADOR RESPONSÁVEL:Dra Claudia da Costa Leite

CARGO/FUNÇÃO: Docente

INSCRIÇÃO CONSELHO REGIONAL Nº 65.349 
UNIDADE DO HCFMUSP: INSTITUTO DE RADIOLOGIA - INRAD

PESQUISADOR EXECUTANTE: Simone Shibao

CARGO/FUNÇÃO: médica

INSCRIÇÃO CONSELHO REGIONAL NNo 75.994

UNIDADE DO HCFMUSP: INSTITUTO DE RADIOLOGIA - INRAD

3. AVALIAÇÃO DO RISCO DA PESQUISA:

$\begin{array}{llll}\text { SEM RISCO } & \square & \text { RISCO MÍNIMO } & X \\ \text { RISCO BAIXO } & \square & \text { RISCO MAIOR } & \square\end{array}$

(probabilidade de que o indivíduo sofra algum dano como consequência imediata ou tardia do estudo)

4.DURAÇÃO DA PESQUISA : 4 anos

\section{III - REGISTRO DAS EXPLICAÇÕES DO PESQUISADOR AO PACIENTE OU SEU REPRESENTANTE LEGAL SOBRE A PESQUISA CONSIGNANDO:}

1. Justificativa e os objetivos da pesquisa

Os pacientes com suspeita clínica ou diagnóstico de encefalopatia mitocondrial (EM) apresentam alteraçoes encefálicas que são lesoes e alterações em substâncias neste órgão. Para identificar estas alteraçoes é necessária a realização de Ressonância Magnética (RM). Uma das substâncias que pode estar aumentada no encéfalo é o lactato e para confirmar que este está alterado é necessária a dosagem deste no líquor e no sangue.

2. Procedimentos que serão utilizados e propósitos, incluindo a identificação dos procedimentos que são experimentais

\section{Serão realizados:}

1- Ressonância Magnética: é o exame de imagem que possibilita o estudo da morfologia do encéfalo e a avaliação de lesões neste órgão. A espectroscopia por RM (ERM) é uma parte deste exame que permite a análise de algumas substâncias no encéfalo que podem estar alteradas na EM e assim auxiliar no diagnóstico e no controle do tratamento da doença. O paciente fará o exame de Ressonância Magnética, deitando-se numa maca. O exame dura cerca de 25 a 30 minutos. Ao entrar no aparelho é recomendável que o paciente feche os olhos por um instante. O tamanho do aparelho é fixo e suficiente para o tamanho de uma pessoa, não sendo possível se fechar sobre a pessoa. O paciente não poderá se mexer durante a realização do exame. Poderá chamar o médico pela campainha ou pelo altofalante. Durante o exame o aparelho produz um som como batidas. 
2- Dosagem sérica de lactato: é um exame de sangue que permite verificar se esta substância está aumentada na circulação, pois isto pode acontecer nos pacientes com EM principalmente em quadros de piora da doença. É um exame simples que consiste apenas de tirar um pouco de sangue de uma veia do braço.

3- Dosagem do lactato liquórico: é um exame do líquido que banha o encéfalo e permite verificar se esta substância está aumentada na circulação, pois isto pode acontecer nos pacientes com EM. É um exame necessário e sempre é realizado tanto para o diagnóstico como também no acompanhamento da doença.

\section{Desconfortos e riscos esperados}

A RM não apresenta nenhum risco ao paciente, pois nao utiliza radiação ionizante $(R X)$ e é um exame amplamente utilizado nos dias de hoje para avaliação de muitas doenças. O paciente pode se incomodar com o som do aparelho e por isso é dado ao paciente um protetor para os ouvidos antes do início do exame. Se preferir o doador pode permanecer com os olhos fechados durante o exame se se incomodar com 0 aparelho Os pacientes que são portadores de marcapasso, certos tipos de prótese de ouvido que são fixas (implante coclear) ou que tenham sofrido ferimento com serra, farpas metálicas, estilhaços ou arma de fogo em certas partes do corpo não podem realizar o exame.

O exame de sangue e do líquor para dosagem do lactato também são exames já realizados rotineiramente em pacientes em acompanhamento neurológico e necessários para os pacientes EM. O exame do líquor, sempre que o paciente for submetido a anestesia para a realizacao da RM, terá sua coleta também realizada sob procedimento anestésico, por ser um procedimento que é um pouco doloroso e assim ser menos desconfortável.

\section{Benefícios que poderão ser obtidos}

A RM é um exame necessário e fundamental na investigação diagnóstica das EM. É o exame que permite a avaliação da existência do comprometimento do encéfalo. Também é o exame que possibilita o acompanhamento da evolução da doença para verificar a estabilidade ou a progressão das lesões. A ERM, caso seja comprovado que posssibilita a dosagem adequada do lactato, pode trazer vantagens no acompanhamento e até mesmo no tratamento da doença e, eventualmente no futuro, permita que o paciente realize um menor número de punções liquóricas para evidenciar a atividade da doença.

5. Procedimentos alternativos que possam ser vantajosos para o indivíduo

\section{IV - ESCLARECIMENTOS DADOS PELO PESQUISADOR SOBRE GARANTIAS DO SUJEITO DA PESQUISA CONSIGNANDO:}

1. Acesso, a qualquer tempo, às informações sobre procedimentos, riscos e benefícios relacionados à pesquisa, inclusive para dirimir eventuais dúvidas. 
2. Liberdade de retirar seu consentimento a qualquer momento e de deixar de participar do estudo, sem que isto traga prejuízo à continuidade da assistência.

3. Salvaguarda da confidencialidade, sigilo e privacidade.

4. Disponibilidade de assistência no HCFMUSP, por eventuais danos à saúde, decorrentes da pesquisa.

5. Viabilidade de indenização por eventuais danos à saúde decorrentes da pesquisa.

V. INFORMAÇÕES DE NOMES, ENDEREÇOS E TELEFONES DOS RESPONSÁVEIS PELO ACOMPANHAMENTO DA PESQUISA, PARA CONTATO EM CASO DE INTERCORRÊNCIAS CLÍNICAS E REAÇÕES ADVERSAS.

VI. OBSERVAÇÕES COMPLEMENTARES

\section{VII - CONSENTIMENTO PÓS-ESCLARECIDO}

Declaro que, após convenientemente esclarecido pelo pesquisador e ter entendido o que me foi explicado, consinto em participar do presente Protocolo de Pesquisa.

São Paulo, de de 


$$
8 \text { - Referências }
$$


Abe K, Inui T, Hirono N, Mezaki T, Kobayashi Y, Kameyama M. Fluctuating MR images with mitochondrial encephalopathy, lactic acidosis, stroke-like syndrome (MELAS). Neuroradiology. 1990;32(1): 77.

Anderson S, Bankier AT, Barrell BG, de Bruikn MH, Coulson AR, Drouin J, Eperon IC, Nierlich DP, Roe BA, Sanger F, Schreier PH, Smith AJ, Standen R, Young IG. Sequence and organization of the human mitochondrial genome. Nature. 1981;290(5806): 457-65.

Barkovich AJ. Toxic and metabolic brain disorders. In: Barkovich AJ. Pediatric Neuroimaging. 4th ed. Philadelphia: Lippincott Williams \& Wilkins; 2005.

Barkovich AJ, Good WV, Koch TK, Berg BO. Mitochondrial disorders: analysis of their clinical and imaging characteristics. AJNR Am J Neuroradiol. 1993;14(5): 1119-37.

Barshop BA. Metabolomic approaches to mitochondrial disease: correlation of urine organic acids. Mitochondrion. 2004; 4(5-6): 521-7.

Baslow MH, Guilfoyle DN Functions of N-acetylaspartate and Nacetylaspartylglutamate in brain: evidence of a role in maintenance of higher brain integrative activities of information processing and cognition. Adv Exp Med Biol. 2006;576: 95-112; discussion 361-3.

Benoist JF, Alberti C, Leclercq S, Rigal O, Jean-Louis R, Ogier de Baulny H, Porquet D, Biou D. Cerebrospinal fluid lactate and pyruvate concentrations and their

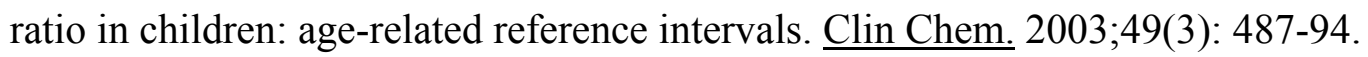

Betts J, Lightowlers RN, Turnbull DM. Neuropathological aspects of mitochondrial DNA disease. Neurochem Res. 2004;29(3): 505-11. 
Bluml S. In vivo quantitation of cerebral metabolite concentrations using natural abundance 13C MRS at 1.5 T. J Magn Reson. 1999;136(2): 219-25.

Braun KP, Gooskens RH, Vandertop WP, Tulleken CA, van der Grond J. 1H magnetic resonance spectroscopy in human hydrocephalus. J Magn Reson Imaging. 2003;17(3): 291-9.

Brooks WM, Friedman SD, Stidley CA. Reproducibility of 1H-MRS in vivo. Magn Reson Med. 1999;41(1): 193-7.

Burton BK. Inborn errors of metabolism in infancy: a guide to diagnosis. Pediatrics. 1998;102(6): E69.

Carod-Artal FJ, Lopez Gallardo E, Solano A, Dahmani Y, Herrero MD, Montoya J. [Mitochondrial DNA deletions in Kearns-Sayre syndrome]. Neurologia. 2006;21(7): 357-64.

Castillo M, Kwock L, Green C. MELAS syndrome: imaging and proton MR spectroscopic findings. AJNR Am J Neuroradiol 1995;16(2): 233-9.

Castillo M, Kwock L, Mukherji SK. Clinical applications of proton MR spectroscopy. AJNR Am J Neuroradiol. 1996;17(1): 1-15.

Castillo M, Kwock L, Scatliff J, Mukherji SK. Proton MR spectroscopy in neoplastic and non-neoplastic brain disorders. Magn Reson Imaging Clin N Am. 1998;6(1):120.

Castillo M, Smith JK, Kwock L. Correlation of myo-inositol levels and grading of cerebral astrocytomas. AJNR Am J Neuroradiol. 2000;21(9): 1645-9. 
Chinnery PF. New approaches to the treatment of mitochondrial disorders. Reprod Biomed Online. 2004;8(1): 16-23.

Cross JH, Gadian DG, Connelly A, Leonard JV. Proton magnetic resonance spectroscopy studies in lactic acidosis and mitochondrial disorders. $\underline{\mathrm{J} \text { Inherit Metab }}$ Dis 1993;16(4): 800-11.

Damadian R. Tumor detection by nuclear magnetic resonance. Science 1971;171(976): 1151-3.

Danielsen ER, Ross B. Magnetic resonance spectroscopy diagnosis of neurological diseases. New York: Marcel Dekker; 1999.

De Graaf RA. In vivo NMR spectroscopy: principles and techniques. New York: Wiley; 1998.

De Stefano N, Matthews PM, Arnold DL. Reversible decreases in N-acetylaspartate after acute brain injury. Magn Reson Med. 1995;34(5): 721-7.

Demougeot C, Marie C, Giroud M, Beley A. N-acetylaspartate: a literature review of animal research on brain ischaemia. J Neurochem 2004;90(4): 776-83.

DiMauro SBE. Mitochondrial disorders due to mutations in the mitochondrial genome. Philadelphia: Butterworth-Heinemann; 2003.

DiMauro S, Bonilla E, De Vivo DC. Does the patient have a mitochondrial encephalomyopathy? J Child Neurol 1999;14 Suppl 1: S23-35.

DiMauro SHM, Hirano M, Kaufmann P. Clinical features and genetics of myoclonic epilepsy with ragged red fibers. In: Fahn S, Frucht SJ. Myoclonus and paroxysmal dyskinesia. Philadelphia: Lippincott Williams \& Wilkins; 2002. p.217-229. 
DiMauro S, Schon EA. Mitochondrial disorders in the nervous system. Annu Rev Neurosci. 2008;31: 91-123.

Duyn JH, Gillen J, Sobering G, van Zijl PC, Moonen CT. Multisection proton MR spectroscopic imaging of the brain. Radiology 1993;188(1): 277-82.

Feng F, You H, Gao J, Li XZ, Meng CL, Sun HY, Jin ZY, Guo YP. Evaluation of mitochondrial encephalomyopathy with lactic acidosis and stroke-like episodes with magnetic resonance imaging and proton magnetic resonance spectroscopy. Chin Med Sci J. 2006;21(4): 234-8.

Filosto M, Mancuso M. Mitochondrial diseases: a nosological update. Acta Neurol Scand 2007;115(4): 211-21.

Filosto M, Tomelleri G, Tonin P, Scarpelli M, Vattemi G, Rizzuto N, Padovani A, Simonati A. Neuropathology of mitochondrial diseases. Biosci Rep 2007;27(1-3): 23-30.

Finsterer J. Central nervous system manifestations of mitochondrial disorders. Acta Neurol Scand 2006;114(4): 217-38.

Fukuhara N, Tokiguchi S, Shirakawa K, Tsubaki T. Myoclonus epilepsy associated with ragged-red fibres (mitochondrial abnormalities ): disease entity or a syndrome? Light-and electron-microscopic studies of two cases and review of literature. $\underline{\mathrm{J}}$ Neurol Sci. 1980;47(1): 117-33.

Gasparovic C, Arfai N, Smid N, Feeney DM. Decrease and recovery of Nacetylaspartate/creatine in rat brain remote from focal injury. $\mathrm{J}$ Neurotrauma. 2001;18(3): 241-6. 
Gerber J, Tumani H, Kolenda H, Nau R. Lumbar and ventricular CSF protein, leukocytes, and lactate in suspected bacterial CNS infections. Neurology. 1998;51(6): 1710-4.

Gillis L, Kaye E. Diagnosis and management of mitochondrial diseases. Pediatr Clin North Am. 2002;49(1): 203-19.

Hanna MG, Nelson IP. Genetics and molecular pathogenesis of mitochondrial respiratory chain diseases. Cell Mol Life Sci. 1999;55(5): 691-706.

Harte MK, Bachus SB, Reynolds GP. Increased N-acetylaspartate in rat striatum following long-term administration of haloperidol. Schizophr Res. 2005;75(2-3): 303-8.

Hendee WR. Cross sectional medical imaging: a history. Radiographics. 1989;9(6): 1155-80.

Inao S, Marmarou A, Clarke GD, Andersen BJ, Fatouros PP, Young HF. Production and clearance of lactate from brain tissue, cerebrospinal fluid, and serum following experimental brain injury. J Neurosurg 1988;69(5): 736-44.

Isobe T, Matsumura A, Anno I, Kawamura H, Shibata Y, Muraishi H, Minami M. Lactate quantification by proton magnetic resonance spectroscopy using a clinical MRI machine: a basic study. Australas Radiol 2007;51(4): 330-3.

Ito S, Shirai W, Asahina M, Hattori T. Clinical and brain MR imaging features focusing on the brain stem and cerebellum in patients with myoclonic epilepsy with ragged-red fibers due to mitochondrial A8344G mutation. AJNR Am J Neuroradiol. 2008;29(2): 392-5. 
Jackson MJ, Schaefer JA, Johnson MA,Morris AA, Turnbull DM, Bindoff LA. Presentation and clinical investigation of mitochondrial respiratory chain disease. A study of 51 patients. Brain 1995;118(Pt 2): 339-57.

Jacobs LJ, de Wert G, Geraedts JP, de Coo IF, Smeets HJ. The transmission of OXPHOS disease and methods to prevent this. Hum Reprod Update. 2006;12(2): 119-36.

Jacobs MA, Ibrahim TS, Ouwerkerk R. AAPM/RSNA physics tutorials for residents: MR imaging: brief overview and emerging applications. Radiographics 2007;27(4): 1213-29.

Jose da Rocha A, Tulio Braga F, Maia A Jr CM, Silva C J, Toyama C, Gama HPP, Kok F, Gomes HR. Lactate detection by MRS in mitochondrial encephalopathy: optimization of technical parameters. J Neuroimaging 2008;18(1): 1-8.

Kanowski M, Kaufmann J, Braun J, Bernarding J, Tempelmann C. Quantitation of simulated short echo time $1 \mathrm{H}$ human brain spectra by LCModel and AMARES. Magn Reson Med. 2004;51(5): 904-12.

Kaufmann P, Koga Y, Shanske S, Hirano M, DiMauro S, King MP, Schon EA. Mitochondrial DNA and RNA processing in MELAS. Ann Neurol 1996;40(2): 17280.

Kearns TP, Sayre GP. Retinitis pigmentosa, external ophthalmophegia, and complete heart block: unusual syndrome with histologic study in one of two cases. AMA Arch Ophthalmol 1958;60(2): 280-9.

Keranen T, Kuusisto H. NARP syndrome and adult-onset generalised seizures. Epileptic Disord 2006;8(3): 200-3. 
Kim IO, Kim JH, Kim WS, Hwang YS, Yeon KM, Han MC. Mitochondrial myopathy-encephalopathy-lactic acidosis-and strokelike episodes (MELAS) syndrome: CT and MR findings in seven children. AJR Am J Roentgenol 1996;166(3): 641-5.

Krageloh-Mann I, Grodd W, Schöning M, Marquard K, Nägele T, Ruitenbeek W. Proton spectroscopy in five patients with Leigh's disease and mitochondrial enzyme deficiency. Dev Med Child Neurol 1993;35(9): 769-76.

Kuriyama M, Umezaki H, Fukuda Y, Osame M, Koike K, Tateishi J, Igata A. Mitochondrial encephalomyopathy with lactate-pyruvate elevation and brain infarctions. Neurology 1984;34(1): 72-7.

Kwock L. Localized MR spectroscopy: basic principles. Neuroimaging Clin N Am 1998;8(4): 713-31.

LaManna JC, Harrington JF, Vendel LM, Abi-Saleh K, Lust WD, Harik SI. Regional blood-brain lactate influx. Brain Res 1993;614(1-2): 164-70.

Lauterbur PC. Image formation by induced local interactions. Examples employing nuclear magnetic resonance. 1973. Clin Orthop Relat Res. 1989;(244): 3-6.

Leigh D. Subacute necrotizing encephalomyelopathy in an infant. J Neurol Neurosurg Psychiatry 1951;14(3): 216-21.

Leonard JV, Schapira AH. Mitochondrial respiratory chain disorders II: neurodegenerative disorders and nuclear gene defects. Lancet 2000;355(9201): 38994.

Lexa FJ, Braffman TJ, Atlas SW. The aging brain and neurodegenerative diseases. Philadelphia: Lippincott-Raven; 1996. 
Li BS, Babb JS, Soher BJ, Maudsley AA, Gonen O. Reproducibility of 3D proton spectroscopy in the human brain. Magn Reson Med 2002;47(3): 439-46.

Lin DD, Crawford TO, Barker PB. Proton MR spectroscopy in the diagnostic evaluation of suspected mitochondrial disease. AJNR Am J Neuroradiol 2003;24(1): $33-41$.

Luft R. The development of mitochondrial medicine. Proc Natl Acad Sci USA 1994;91(19): 8731-8.

Luft R, Ikkos D, Palmieri G, Ernster L, Afzelius B. A case of severe hypermetabolism of nonthyroid origin with a defect in the maintenance of mitochondrial respiratory control: a correlated clinical, biochemical, and morphological study. J Clin Invest 1962;41: 1776-804.

Macchia RJ, Termine JE, Buchen CD. Raymond V. Damadian, M.D.: magnetic resonance imaging and the controversy of the 2003 Nobel Prize in Physiology or Medicine. J Urol 2007;178(3 Pt 1): 783-5.

Madhavarao CN, Chinopoulos $\mathrm{C}$, Chandrasekaran $\mathrm{K}$, Namboodiri MA. Characterization of the $\mathrm{N}$-acetylaspartate biosynthetic enzyme from rat brain. $\underline{\mathrm{J}}$ Neurochem 2003;86(4): 824-35.

Madhavarao CN, Moffett JR, Moore RA, Viola RE, Namboodiri MA, Jacobowitz DM. Immunohistochemical localization of aspartoacylase in the rat central nervous system. J Comp Neurol 2004;472(3):318-29.

Mancuso M, Ferraris S, Pancrudo J, Feigenbaum A, Raiman J, Christodoulou J, Thorburn DR, DiMauro S. New DGK gene mutations in the hepatocerebral form of mitochondrial DNA depletion syndrome. Arch Neurol 2005;62(5):745-7. 
Mannan AA, Sharma MC, Shrivastava P, Ralte AM, Gupta V, Behari M, Sarkar C. Leigh's syndrome. Indian J Pediatr 2004;71(11): 1029-33.

Marshall I, Wardlaw J, Cannon J, Slattery J, Sellar RJ. Reproducibility of metabolite peak areas in 1H MRS of brain. Magn Reson Imaging 1996;14(3): 281-92.

Mathews PM, Andermann F, Silver K, Karpati G, Arnold DL. Proton MR spectroscopic characterization of differences in regional brain metabolic abnormalities in mitochondrial encephalomyopathies. Neurology 1993;43(12): 248490.

Matthews PM, Tampieri D, Berkovic SF, Andermann F, Silver K, Chityat D, Arnold DL. Magnetic resonance imaging shows specific abnormalities in the MELAS syndrome. Neurology 1991;41(7): 1043-6.

McClure RJ, Kanfer JN, Panchalingam K, Klunk WE, Pettegrew JW. Magnetic resonance spectroscopy and its application to aging and Alzheimer's disease. Neuroimaging Clin N Am 1995;5(1): 69-86.

Miyake M, Kakimoto Y. Developmental changes of N-acetyl-L-aspartic acid, Nacetyl-alpha-aspartylglutamic acid and beta-citryl-L-glutamic acid in different brain regions and spinal cords of rat and guinea pig. J Neurochem 1981;37(4): 1064-7.

Miyake M, Kakimoto Y, Sorimachi M. A gas chromatographic method for the determination of N-acetyl-L-aspartic acid, N-acetyl-alpha-aspartylglutamic acid and beta-citryl-L-glutamic acid and their distributions in the brain and other organs of various species of animals. J Neurochem 1981;36(3): 804-10.

Moffett JR, Ross B, Arun P, Madhavarao CN, Namboodiri AM. N-Acetylaspartate in the CNS: from neurodiagnostics to neurobiology. Prog Neurobiol 2007;81(2): 89131. 
Morava E, Hogeveen M, De Vries M, Ruitenbeek W, de Boode WP, Smeitink J. Normal serum alanine concentration differentiates transient neonatal lactic acidemia from an inborn error of energy metabolism. Biol Neonate 2006;90(3): 207-9.

Morgan-Hughes JA. Skeletal Muscle Pathology. Edinburgh: Churchill Livingstone; 1982.

Moslemi AR, Darin N. Molecular genetic and clinical aspects of mitochondrial disorders in childhood. Mitochondrion 2007;7(4): 241-52.

Nagae-Poetscher LM, McMahon M, Braverman N, Lawrie WT Jr, Fatemi A, Degaonkar M, Horská A, Pomper MG, Chacko VP, Barker PB. Metabolites in ventricular cerebrospinal fluid detected by proton magnetic resonance spectroscopic imaging. J Magn Reson Imaging 2004;20(3): 496-500.

Nakamura S, Yoshinari M, Wakisaka M, Kodera H, Doi Y, Yoshizumi H, Asano T, Iwase M, Mihara F, Fujishima M. Ketoacidosis accompanied by epileptic seizures in a patient with diabetes mellitus and mitochondrial myopathy, encephalopathy, lactic acidosis and stroke-like episodes (MELAS). Diabetes Metab 2000;26(5): 407-10.

Nass S, Nass MM. Intramitochondrial fibers with DNA characteristics. II. Enzymatic and other hydrolytic treatments. J Cell Biol 1963;19: 613-29.

Ohshita T, Oka M, Imon Y, Watanabe C, Katayama S, Yamaguchi S, Kajima T, Mimori Y, Nakamura S. Serial diffusion-weighted imaging in MELAS. Neuroradiology 2000;42(9): 651-6.

Oppenheim C, Galanaud D, Samson Y, Sahel M, Dormont D, Wechsler B, Marsault C. Can diffusion weighted magnetic resonance imaging help differentiate stroke from stroke-like events in MELAS? J Neurol Neurosurg Psychiatry 2000;69(2): 248-50. 
Palasis S, Grattan-Smith D, Shoffner J, Neish A, Stewart S. Mitochondrial disorders of oxidative phosphorylation: patterns of disease; 2001. Disponível em: http://www.neurographics.org/Palasis/1.shtml

Pan JW, Takahashi K. Interdependence of N-acetyl aspartate and high-energy phosphates in healthy human brain. Ann Neurol 2005;57(1): 92-7.

Park SB, Ma KT, Kook KH, Lee SY. Kearns-Sayre syndrome -3 case reports and review of clinical feature. Yonsei Med J 2004;45(4): 727-35.

Patel TB, Clark JB. Synthesis of N-acetyl-L-aspartate by rat brain mitochondria and its involvement in mitochondrial/cytosolic carbon transport. Biochem J. 1979;184(3): $539-46$.

Pavlakis SG, Kingsley PB, Kaplan GP, Stacpoole PW, O'Shea M, Lustbader D. Magnetic resonance spectroscopy: use in monitoring MELAS treatment. Arch Neurol 1998;55(6): 849-52.

Pavlakis SG, Phillips PC, DiMauro S, De Vivo DC, Rowland LP. Mitochondrial myopathy, encephalopathy, lactic acidosis, and strokelike episodes: a distinctive clinical syndrome. Ann Neurol 1984;16(4): 481-8.

Pincus JH. Subacute necrotizing encephalomyelopathy (Leigh's disease): a consideration of clinical features and etiology. Dev Med Child Neurol 1972;14(1): 87-101.

Posner JB, Plum F. Independence of blood and cerebrospinal fluid lactate. Arch Neurol 1967;16(5): 492-6.

Provencher SW. Estimation of metabolite concentrations from localized in vivo proton NMR spectra. Magn Reson Med 1993;30(6): 672-9. 
Ricoy-Campo JR, Cabello A. [Mitochondriopathies]. Rev Neurol 2003;37(8): 775-9.

Rosen L, Phillips S, Enzmann D. Magnetic resonance imaging in MELAS syndrome. Neuroradiology 1990;32(2): 168-71.

Rosing HS, Hopkins LC, Wallace DC, Epstein CM, Weidenheim K. Maternally inherited mitochondrial myopathy and myoclonic epilepsy. Ann Neurol 1985;17(3): 228-37.

Ross B, Bluml S. Magnetic resonance spectroscopy of the human brain. Anat Rec 2001;265(2): 54-84.

Schatz G. The isolation of possible mitochondrial precursor structures from aerobically grown baker's yeast. Biochem Biophys Res Commun 1963;12: 448-51.

Scholte HR. The biochemical basis of mitochondrial diseases. J Bioenerg Biomembr 1988;20(2):161-91.

Shoffner JM, Lott MT, Lezza AM, Seibel P, Ballinger SW, Wallace DC. Myoclonic epilepsy and ragged-red fiber disease (MERRF) is associated with a mitochondrial DNA tRNA(Lys) mutation. Cell 1990;61(6): 931-7.

Simmons ML, Frondoza CG, Coyle JT. Immunocytochemical localization of Nacetyl-aspartate with monoclonal antibodies. Neuroscience 1991;45(1): 37-45.

Soher BJ, Hurd RE, Sailasuta N, Barker PB. Quantitation of automated single-voxel proton MRS using cerebral water as an internal reference. Magn Reson Med 1996;36(3): 335-9. 
Sommer JB, Gaul C, Heckmann J, Neundörfer B, Erbguth FJ. Does lumbar cerebrospinal fluid reflect ventricular cerebrospinal fluid? A prospective study in patients with external ventricular drainage. Eur Neurol 2002;47(4): 224-32.

Spiro AJ, Prineas JW, Moore CL. A new mitochondrial myopathy in a patient with salt craving. Arch Neurol 1970;22(3): 259-69.

Stacpoole PW, Bunch ST, Neiberger RE, Perkins LA, Quising R, Hutson AD, Greer M. The importance of cerebrospinal fluid lactate in the evaluation of congenital lactic acidosis. J Pediatr 1999;134(1): 99-102.

Steen RG, Ogg RJ Abnormally high levels of brain N-acetylaspartate in children with sickle cell disease. AJNR Am J Neuroradiol 2005;26(3): 463-8.

Sue CM, Crimmins DS, Soo YS, Pamphlett R, Presgrave CM, Kotsimbos N, JeanFrancois MJ, Byrne E, Morris JG. Neuroradiological features of six kindreds with MELAS tRNA(Leu) A2343G point mutation: implications for pathogenesis. J Neurol Neurosurg Psychiatry 1998;65(2): 233-40.

Tallan HH. Studies on the distribution of N-acetyl-L-aspartic acid in brain. $\underline{\mathrm{J} \text { Biol }}$ Chem 1957;224(1): 41-5.

Taylor DL, Davies SE, Obrenovitch TP, Urenjak J, Richards DA, Clark JB, Symon L. Extracellular N-acetylaspartate in the rat brain: in vivo determination of basal levels and changes evoked by high K+. J Neurochem 1994;62(6): 2349-55.

Truckenmiller ME, Namboodiri MA, Brownsein MJ, Neale JH. N-Acetylation of Laspartate in the nervous system: differential distribution of a specific enzyme. $\underline{\mathbf{J}}$ Neurochem 1985;45(5): 1658-62. 
Urenjak J, Williams SR, Gadian DG, Noble M. Specific expression of Nacetylaspartate in neurons, oligodendrocyte-type-2 astrocyte progenitors, and immature oligodendrocytes in vitro. J Neurochem 1992;59(1): 55-61.

Valanne L, Ketonen L, Majander A, Suomalainen A, Pihko H. Neuroradiologic findings in children with mitochondrial disorders. AJNR Am J Neuroradiol 1998;19(2): 369-77.

Van Maldergem L, Trijbels F, DiMauro S, Sindelar PJ, Musumeci O, Janssen A, Delberghe X, Martin JJ, Gillerot Y. Coenzyme Q-responsive Leigh's encephalopathy in two sisters. Ann Neurol 2002;52(6): 750-4.

von Kleist-Retzow JC, Schauseil-Zipf U, Michalk DV, Kunz WS. Mitochondrial diseases--an expanding spectrum of disorders and affected genes. Exp Physiol 2003;88(1): 155-66.

Wang ZJ, Zimmerman RA. Proton MR spectroscopy of pediatric brain metabolic disorders. Neuroimaging Clin N Am 1998;8(4): 781-807.

Yang YL, Sun F, Zhang Y, Qian N, Yuan Y, Wang ZX, Qi Y, Xiao JX, Wang XY, Qi ZY, Zhang YH, Jiang YW, Bao XH, Qin J, Wu XR. Clinical and laboratory survey of 65 Chinese patients with Leigh syndrome. Chin Med J (Engl) 2006;119(5): $373-7$.

Yonemura K, Hasegawa Y, Kimura K, Minematsu K, Yamaguchi T. Diffusionweighted MR imaging in a case of mitochondrial myopathy, encephalopathy, lactic acidosis, and strokelike episodes. AJNR Am J Neuroradiol 2001;22(2): 269-72.

Zeviani M, Di Donato S. Mitochondrial disorders. Brain 127(Pt 10): 2004;2153-72. 
Zhang Y, Yang YL, Sun F, Cai X, Qian N, Yuan Y, Wang ZX, Qi Y, Xiao JX, Wang XY, Zhang YH, Jiang YW, Qin J, Wu XR. Clinical and molecular survey in 124 Chinese patients with Leigh or Leigh-like syndrome. J Inherit Metab Dis 2007;30(2): 265.

Zhu Z, Yao J, Johns T, Fu K, De Bie I, Macmillan C, Cuthbert AP, Newbold RF, Wang J, Chevrette M, Brown GK, Brown RM, Shoubridge EA. SURF1, encoding a factor involved in the biogenesis of cytochrome c oxidase, is mutated in Leigh syndrome. Nat Genet 1998;20(4): 337-43.

Zimmerman RA, Wang ZJ. The value of proton MR spectroscopy in pediatric metabolic brain disease. AJNR Am J Neuroradiol 1997;18(10): 1872-9.

Zschocke J, Hoffmann GF. Vademecum Metabolicum Manual de Pediatria Metabólica. Heidelberg - Alemanha; 2004. 